\title{
Effect of Fiber Stripes of COVID-19 Healthy Personal Materials On Durability, And Physicomechanical Characteristic of Concrete For Decorative Landscape Pavements And Artificial Rocks
}

Ahmed Abd El aal ( $\sim$ Ahmed_aka80@yahoo.com )

Najran University

\section{Research Article}

Keywords: Coronavirus pandemic, HPPM stripe, mechanical properties, concrete, architectural forms

Posted Date: October 1st, 2021

DOI: https://doi.org/10.21203/rs.3.rs-867865/v1

License: (9) This work is licensed under a Creative Commons Attribution 4.0 International License. Read Full License 


\section{Abstract}

This research presents a new method for determining the impact of healthy personal protection materials HPPM stripes, such as surgical masks, protective suits, overhead and safety foot shoes, on the durability, physicomechanical characteristics of concrete for use in architectural forms. As a result of the current global epidemic caused by Coronavirus, the use of (HPPM) such as surgical masks, protective suits, overhead and safety foot shoes has increased considerably (COVID-19). COVID-19's second and third waves are currently affecting various countries, necessitating the use of face masks (FM). As a result, millions of single FS have been discharged into the wild, washing up on beaches, floating beneath the seas, and winding up in hazardous locations. The effect of stripes fibers on physicomechanical aspects of concrete, such as workability, UCS, FS, IMs, spalling, and AbR; sorptivity, Sw; n; water penetration, permeability, and economic and eco-friendly aspects, was also discussed. With a focus on HPPM especially single-use face masks, this research investigates an innovative way for incorporating pandemic waste into concrete structures. SEM and XRD were also employed to analyze microstructures and the interfacial transition zone, as well as to identify the elements. HPPM was found to have a poreblocking effect, which reduced permeability and capillary porosity. It was also discovered that the best concentrations of HPPM, particularly masks, were applied by volume at $0 \%, 0.1,1.5,2.0$, and $2.5 \%$. The usage of single-use face masks increased the strength qualities and overall performance of the concrete samples. The tendency of growing strength began to disappear around $2 \%$. The results of this investigation show that stripe content has no effect on compressive strength. The stripe, on the other hand, is critical in determining the flexural strength of concrete. A SEM was used to analyze the microstructure of concrete. HPPM fibers are discovered to act as bridges across cracks, enhancing the matrixes transfer capability. From a technological and environmental standpoint, the study found that using healthy personal protection materials fiber in the production of concrete is viable.

\section{Highlights}

- The effect of a polypropylene (HPPM) stripes on architectural shapes performance is investigated.

- Fibers could not participate in any chemical reactions, according to SEM and XRD.

- Influence of HPPM fibers on crack blocking of concrete was investigated.

- Effect of HPPM fibers on permeability of cracked concrete was studied.

- The pore-blocking impact of fibers may diminish permeability and capillary porosity.

\section{Introduction}

Concrete has a strong compressive strength but a tensile strength of ten times that of steel. It also has a brittle property that prevents stress transmission after cracking. It is feasible to add fibers to the concrete mix in order to prevent brittle failure and increase mechanical qualities. HPPM stripes are cementitious composite material having fibers scattered throughout, such as steel, polymer, polypropylene, carbon, glass, and others (Blazy and R. Blazy 2021). The steel bars protection from corrosion and sulfate attack, 
as well as water and ions infiltration through pores as well as cracks, is linked to improving the longevity of reinforced concrete (Kumar Mehta and Burrows, 2001). Plastic shrinkage at an early age is commonly acknowledged as one of the principal causes of concrete cracks. As a result, both the insertion of fibers and the replacement of traditional reinforcement with fibers appear to be quite favorable in terms of longterm development (Blazy and R. Blazy 2021). Polypropylene fiber reinforced concrete was investigated by Islam and Gupta (2016) in an experiment. Compressive strength fell marginally over the testing period after the addition of $3 \%$ polypropylene stripeby volume, with the most significant reduction being $10 \%$. Splitting tensile strength improved by $39 \%$ while compressive strength reduced with the inclusion of $1 \%$ polypropylene stripe by volume.

Researchers have mentioned a number of benefits of employing HPPM in concrete mixtures, but few experimental studies on enhancing the durability and engineering qualities of concrete for use in architectural forms for public spaces have been carried out.

Many studies (Soutsos et al 2012) refer to the concept of an optimally constructed mix, which achieves a balance of workability and strength. When it comes to understanding FRC behavior, fiber size and slenderness are critical. Increasing the aspect ratio of steel fibers from 65 to 80 increased modulus of elasticity, flexural tensile strength, and toughness by $0.32-7.16 \%, 0.63-50.97 \%$, and $32.06-155.32 \%$, respectively, depending on the number of fibers and silica fume, according to (Garca et al 2014). The work of took into account different fiber volumes $(0.5,1.0$, and 1.5 percent $)$ as well as slenderness $(45,65$, and 80). (Yazici et al. 2007). In compared to the fiber with the smallest slenderness, the scientists found that increasing quantity of the fiber increased compressive, tensile, and flexural strength by 10,14 , and 58 $\%$, respectively. Furthermore, based on the findings of Garca-Tengua (2014), thin fibers may be a viable solution for reducing creep strain. The efficiency of the fibers is determined not only by the metrics listed above, but also by their concrete bonding strength (Yin et al. 2015). In addition, the fibers can be crimped, twisted, sinusoidal, or hooked to improve the contact surface with the matrix, and their indents can be fibrillated (the ends split while mixing). The mechanical properties of the concrete mixture are also affected by the form of the fiber (Balaguru, H. Najm. 2004).

Xu et al. (2020) conducted similar experiments on fibre reinforced concrete and discovered that when cellulose fibre (CTF) was used in dosages of $1.5 \mathrm{~kg} / \mathrm{m}^{3}$, the concrete's UCS increased to 12 percent, but when polyvinyl alcohol fibre (PF) was used in dosages of around $4.0 \mathrm{~kg} / \mathrm{m}^{3}$, the concrete's UCS reduced by 35 percent. When the dosage was increased to $2.0 \mathrm{~kg} / \mathrm{m}^{3}$, CTF's splitting tensile strength declined by $23 \%$, while PF's decreased by $55 \%$. The splitting tensile strength of polyolefin fibers was also degrading. It should also be noted that the use of fiber reinforcement in concrete imposes specific mix composition constraints, therefore it may be required to make changes (Mohajerani et al 2019). The number, form, and slenderness of the fibers affect the workability of concrete (Markovic, 2006; Karahan and Atiş, 2011; Zych and Krasodomski, 2016; Wan Ibrahim, 2017). It's a promising field of use, particularly in metropolitan locations where there are adverse conditions of environmental, impact of damages, abrasion of surface, and vandalism. HPPM fibers, on the other hand, are more commonly used in architectural applications. 
Specifically, HPPM fibers are particularly successful in reducing plastic shrinkage fractures in the early days of concrete's life and considerably improve concrete's post-cracking behavior.

Researchers have identified a number of benefits of employing HPP in concrete mixtures, but few actual studies on enhancing concrete's durability and engineering qualities for use in building have been conducted. Due to the strong effect of HPPM on concrete behavior, multiple laboratory samples containing various percentages of HPPM were built in the current study utilizing the standard mix design of concrete used in architectural fabrication.

The primary goal of this research is to explore if single-use face masks can be recycled and reused in order to reduce the quantity of pandemic-related garbage that ends up in landfills or littering the streets during the crisis. The impact of HPPM fibers on concrete's physical and mechanical qualities, as well as how HPPM fibers might be employed in a potential sector of application: public spaces. The interdisciplinary study of engineering works and architecture is addressed in this presentation. This is a revolutionary technique that aids in the comprehension and integration of those various areas of knowledge. This research is additionally noteworthy because no previous research on the use of HPPM fibers in public settings has been published.

\section{Materials And Methods \\ 2.1 Materials}

\subsubsection{Cement}

The cement used in this study was Type I ordinary Portland cement from Najran cement (OPC). The specific gravity is cement of 3.15 and a Blaine Fineness of $410 \mathrm{~m}^{2} / \mathrm{kg}$. The Bogue phases of the cement, according to the manufacturer, were $59 \%$ C3S, $12.1 \%$ C2S, $10.6 \%$ C3A, and $10.4 \%$ C4AF. The oxides found in cement are mentioned in Table 1.

Table 1

Cement Chemical composition

\begin{tabular}{|llllllllll|}
\hline Items & $\mathrm{SiO}_{2}$ & $\mathrm{Al}_{2} \mathrm{O}_{3}$ & $\mathrm{Fe}_{2} \mathrm{O}_{3}$ & $\mathrm{CaO}$ & $\mathrm{SO}_{3}$ & $\mathrm{MgO}$ & $\mathrm{K}_{2} \mathrm{O}$ & Insoluble & LOI \\
\hline wt.\% & 19.73 & 6.2 & 3.44 & 63.78 & 2.23 & 0.96 & 1.02 & 0.93 & 1.51 \\
\hline
\end{tabular}

\subsubsection{Aggregates}

For casting the concrete samples that meet with ASTM C33/C33M-18, the fine aggregate gathered from natural sand which have maximum size of $4.75 \mathrm{~mm}$ and the coarser aggregate was natural crushed stone with a maximum size of $20 \mathrm{~mm}$. The physical parameters of the aggregates are listed in Table 2 . Coarse sand was employed as fine aggregate in the concrete samples, whereas crushed stone chips 
complying to ASTM C33 were used as coarse aggregate. Table 2 lists the physical features of the aggregates.

Table 2

Materials properties

\begin{tabular}{|lllll|}
\hline Material & $\begin{array}{l}\text { Fineness } \\
\text { Modulus }\end{array}$ & $\begin{array}{l}\text { Specific } \\
\text { Gravity }\end{array}$ & $\begin{array}{l}\text { Absorption } \\
(\%)\end{array}$ & $\begin{array}{l}\text { Dry rodded } \\
\text { unit weight }\left(\mathrm{kg} / \mathrm{m}^{3}\right)\end{array}$ \\
\hline Coarse Aggregate & - & 2.81 & 0.46 & 1555 \\
\hline Fine Aggregate & 2.43 & 2.63 & 1.65 & 1596 \\
\hline (HPPM) & - & - & 8.8 & -- \\
\hline
\end{tabular}

\subsubsection{Water}

Concrete mixtures and curing is made with potable tap water. The ASTM C1602/C1602M criterion was met for the water's properties.

\subsubsection{Characteristic Of Polypropylene Stripes (Hppm)}

The polypropylene stripes (HPPM) employed in this study are commercially available polypropylene stripes like as (surgical masks, protective suits, overhead lighting, and safety foot shoes), as indicated in Fig. 1. Polypropylene fibres are mixed into concrete at a rate of $2.5 \%$ of the total volume.

\section{3-experimental Program}

The samples mixed with cut-up HPPM were analyzed using a total of six concrete combinations in proportions of $0 \%$ (control mix), $0.5 \%, 1 \%, 1.5 \%, 2 \%$, and $2.5 \%$ by volume of concrete. This choice is in line with prior research by Al-Hadithi and Hilal (2016), Xu et al. (2020), and Islam and Gupta (2016). Najran cement with a specific gravity of 3.15 and a bulk density of $1250-1650 \mathrm{~kg} / \mathrm{m} 3$ was utilized throughout the experiments, as well as coarse aggregate with a nominal size of $20 \mathrm{~mm}$ and fine aggregate with a specific gravity of 2.63 that had been oven-dried for 48 hours at $110^{\circ} \mathrm{C}$ to remove excess moisture. Table 1 lists the parameters of the cement that was used. The physical parameters of HPPM, fine and coarse aggregate are shown in Table 2. However, due to limits imposed by the coronavirus "COVID-19," we are unable to use the HPPM, particularly the face masks described in this study. To limit community transmission and infection risk from coronavirus, new, unused HPPM were utilized in this study. The HPPM were cut into small pieces with a length of $1 \mathrm{~cm}$ and a width of $1 \mathrm{~cm}$ (Fig. 1). 


\section{1- Concrete Mix Proportions}

Table 3 shows the mix pattern used to cast the samples, as well as the varied amounts of HPPM. CM0 denotes a control mix containing no surgical masks, whereas CM 25 denotes concrete with a $2.5 \%$ by volume concentration.

In a normal mixer, concrete samples were prepared according to ASTM C192M with a water/cement ratio of 0.50 . There were no extra materials or chemical admixtures employed in this study. HPPM fibers were employed in the proportions of $0.5 \%, 1 \%, 1.5 \%, 2.0 \%$, and $2.5 \%$ as an extra percentage. Table 3 shows the proportions of the concrete mix. Concrete was mixed and placed into various molds (cubes, cylinders, and prisms) for 24 hours before being demolded and cured in clean drinkable tap water. The concrete samples were cured for 28 days at room temperature (Fig. 1).

Table 3

Mix proportions of concrete

\begin{tabular}{|lllllll|}
\hline Percentage \% & $\mathbf{0}$ & $\mathbf{0 . 5}$ & $\mathbf{1}$ & $\mathbf{1 . 5}$ & $\mathbf{2 . 0}$ & $\mathbf{2 . 5}$ \\
\hline Water & 217 & 217 & 217 & 217 & 217 & 217 \\
\hline Cement & 400 & 400 & 400 & 400 & 400 & 400 \\
\hline Coarse Agg. & 1054 & 1054 & 1054 & 1054 & 1054 & 1054 \\
\hline Fine Agg. & 666 & 666 & 666 & 666 & 666 & 666 \\
\hline HPPM & 0 & 11.68 & 23.36 & 35.04 & 46.72 & 58.4 \\
\hline
\end{tabular}

\section{2-casting And Curing}

All of the dry materials were weighed and then placed in the concrete mixer for three minutes to mix. After 3 minutes of mixing with water, the dry materials were gently added and combined for another 3 minutes. The HPPM fragments were slowly and in small amounts added to the solution during this period to ensure even dispersion and prevent clumping. After being detached from the mixer, the concrete was poured into the cylindrical molds. To avoid concrete adhesion, the inner surfaces of the assembled mold should be thinly coated with mold oil. To allow the concrete to settle, the cylindrical molds were filled with concrete and placed on the vibrating table for 20 seconds. The molds were filled with concrete after the first 20 seconds then vibrated for another 20 seconds to ensure there were no voids. The new concrete surface was finished with a smooth steel trowel. After casting, the samples were covered with a moist Hossain bag and left in the mold for 24 hours at room temperature. The specimens were taken from the molds after 24 hours and immediately submerged in clean fresh water to cure for 28 days, respectively, for the strength test. This procedure was followed for each concrete batch. Previous research (Al-Hadithi 
et al., 2019; Al-Hadithi and Hilal, 2016; Sadiqul Islam and Gupta, 2016) employed identical casting procedures (1).

The concrete samples were removed from the cylinder molds after 24 hours and placed in a curing tank filled with clean, fresh water for the next 28 days at a temperature of roughly 22 degrees Celsius. The concrete samples were removed from the curing tank and allowed to dry for 28 days before being ground back to provide a smooth contact surface with the compression and testing apparatus, as required by ASTM C31/C31M-21. The loading rates vary between 0.14 and $0.34 \mathrm{MPa} / \mathrm{sec}$ (ASTM C39).

\section{3.description Of The Experimental Work}

Compressive, split tensile, and flexural strength testing were conducted using ASTM C39/C39M, ASTM C496/C496M, and ASTM C78/C78M, respectively. The compressive strength test was done on $100 \times 100$ $x 100 \mathrm{~mm} 3$ cube specimens, while the split test was done on $100 \mathrm{~mm}$ diameter, $200 \mathrm{~mm}$ height, and strength test on $100 \mathrm{~mm}$ diameter, $200 \mathrm{~mm}$ height, and strength test on $100 \mathrm{~mm}$ diameter, $200 \mathrm{~mm}$ height, and strength test on $100 \mathrm{~mm}$ diameter, $200 \mathrm{~mm}$ height, and strength test on $100 \mathrm{~mm}$ diameter Flexural strength of $100 \mathrm{~mm}$ diameter, $200 \mathrm{~mm}$ height, and strength of $100 \mathrm{~mm}$ diameter, $200 \mathrm{~mm}$ height, and strength of $100 \mathrm{~mm}$ diameter, $200 \mathrm{~mm}$ height, and strength of $100 \mathrm{~mm}$ diameter, $200 \mathrm{~mm}$ height, and strength of $100 \mathrm{~mm}$ diameter, $200 \mathrm{~mm}$ height, and strength of $100100 \mathrm{~mm}$ diameter, $200 \mathrm{~mm}$ height, and $100 \mathrm{~mm}$ flexural strength Flexural strength of $100 \mathrm{~mm}$ diameter, $200 \mathrm{~mm}$ height, and strength Flexural strength of $100 \mathrm{~mm}$ diameter, $200 \mathrm{~mm}$ height, and strength Flexural strength of $100 \mathrm{~mm}$ diameter, 200 $\mathrm{mm}$ height, and strength The cube specimens were weighed in water immediately after being taken from the water basin, in the saturated surface dry state, and in the dry state to determine the densities of the samples. The compression testing apparatus has a force of 2000 kilograms per square meter. Three samples of each mix configuration were inspected for defects before being subjected to a force of 157 $\mathrm{kN} / \mathrm{min}$. To assess the homogeneity and structural integrity of the manufactured HPPM concrete, nondistractive pulse velocity (PV) testing was done on compression samples in accordance with ASTM C597-16 (2016). The test can be used to assess concrete samples' consistency and uniformity, as well as cracks and voids that are not visible on the surface. To evaluate effective porosity, two to three representative specimens (with individual mass $>50 \mathrm{gm}$ ) from a sample were immersed in water in a desiccator (e). A vacuum pressure more than $800 \mathrm{~Pa}$ (needed by ISRM 2007) was maintained within the desiccator for at least 2 hours to saturate the specimens. The dry (Mdry) and saturated (Msat) masses of the specimen, as well as the saturated specimen suspended in water (Msus), were all calculated. To calculate effective porosity (e) and dry density (dry), the following equations were used: The concrete samples were removed from the cylinder molds after 24 hours and placed in a curing tank filled with clean, fresh water for the next 28 days at a temperature of roughly 22 degrees Celsius. After 28 days of curing, the concrete samples were removed from the curing tank and allowed to dry. The tops of the cylindrical samples were ground back after air drying to produce a smooth contact surface with the compression and testing gear, as per ASTM C31 / C31M-21. The loading rates vary between 0.14 and $0.34 \mathrm{MPa} / \mathrm{sec}$ (ASTM C39). 


$$
\text { ne }=M \text { sat }-M \text { dry } / M \text { (sat) }-M \text { (SUS) }
$$

The Hitachi U8040 Scanning Electron Microscope was used for the scanning electron microscopic (SEM) research. On hardened specimens, the liquid permeability was determined according to EN 12390-08. (2009). A $150 \mathrm{~mm}$ cube specimen was used for the permeability test. Before being measured for permeability, the specimen was cured for 28 days. Figure 1 depicts the experimental setup for all tests.

\section{Results}

HPPM stripes (polypropylene) were utilized in concrete as a crack-resistant improvement material. The HPPM is constructed of plastic polypropylene fibers, according to the producers. It also has a high level of chemical stability and strength. By volume, fiber content ranged from $0.5 \%$ to $2.5 \%$. HPPM were chopped into little pieces of one centimeter in length and one centimeter in width. The physical parameters of the single-use HPPM are listed in Table 4.

Table 4

Physical properties of healthy personal protective materials (HPPM) Shabrian et al., 2021.

\begin{tabular}{|lll|}
\hline Physical properties & SHM & Standard \\
\hline Specific gravity & 0.91 & ASTM D792-20 (2020) \\
\hline Melting point $\left(\mathrm{C}^{\circ}\right)$ & 160 & ASTM D7138-16 (2016) \\
\hline Water absorption 24 $\mathrm{h}(\%)$ & 8.8 & ASTM D570-98 (2018) \\
\hline Tensile strength $(\mathrm{MPa})$ & 3.65 & ASTM D638-14 (2014) \\
\hline Tensile strength at break (MPa) & 3.97 & ASTM D638-14 (2014) \\
\hline Elongation at break (\%) & 118.9 & ASTM D638-14 (2014) \\
\hline Rupture force $(\mathrm{N})$ & 19.46 & ASTM D638-14 (2014) \\
\hline Aspect ratio & 24 & -- \\
\hline
\end{tabular}

\section{1.xrd And Sem Of Hppm Stripes}

Figure $2 a, b$ shows the face mask and HPPM fibers' integrated X-ray diffraction patterns. The diffraction peaks of all fibers were obtained between 10 and 30 degrees, as shown in the Fig. $2 \mathrm{~b}$. The peaks obtained at approximately $14^{\circ}, 17^{\circ}, 18.6^{\circ}, 21-22^{\circ}$, and $28^{\circ}$ are similar to the peaks generated by -polypropylene (JCPDS 00-050-2397- 1970). Any micro structural changes in HPPM were observed using SEM. The HPPM layer (polypropylene) was sliced into a $10 \mathrm{~mm} \times 10 \mathrm{~mm}$ size and examined using a SEM (Hitachi, 
TM3000) at 1000 magnification. Figure 2c shows structural changes in polypropylene fibers such as melting, distortion, tangling, and cracking.

\subsection{XRD results of concrete containing the HPPM fibers.}

Specimens were studied using XRD to show the influence of adding HPPM Fibers to concrete mixtures on phase changes. Figure 3 shows the results of a $2 \%$ HPPM test at the age of 28 days. The crystalline phase, i.e. portlandite $\mathrm{Ca}(\mathrm{OH})_{2}$, calcite $\mathrm{Ca}(\mathrm{CO})_{3}$, and silicon dioxide $\mathrm{SiO}$, are the primary peaks. $\mathrm{Ca}(\mathrm{CO})_{3}$ and $\mathrm{Ca}(\mathrm{OH})_{2}$ levels did not change appreciably when HPPM fibers were added. Similarly, when fibers are added, it is represented at 650 . This phenomenon demonstrates that fibers are incapable of participating in chemical processes. Furthermore, the presence of amorphous materials may be indicated by the convex form between 2theta $=16^{\circ}$ and $36^{\circ}$.

\subsection{Slump}

Figure 4 depicts the slump values for concrete mixtures including various amounts of HPPM as an addition. Slump values are anticipated to decrease linearly as the percentage of HPPM added to concrete increases. In comparison to the reference slump of the reference sample, the slump has decreased by approximately $5 \%, 13 \%, 20 \%, 30 \%$, and $43 \%$, respectively. The decreased slump could be attributed to the HPPM particles' heterogeneity and roughness, which could diminish the fluidity of the mixtures as well as HPPM's high absorption (8.8\%) Fig. 4. Because of HPPM's high porosity (avg. 8.8\%) and high cohesiveness between HPPM and concrete matrix (Das CS, et al. 2018), increasing the amount of HPPM resulted in lower slump values. The volume, form, and slenderness of the fibers, as well as the mix composition, influence the workability of concrete (Markovic, 2006, Karahan and Atiş, 2011 Zych and Krasodomski 2016, Wan Ibrahim 2017, Blazy and Blazy 2012). When the fiber dose exceeds this crucial amount, the likelihood of fiber clamping or balling increases, resulting in uneven fiber distribution and a greater reduction in flowability (Ranjbar and Zhang, 2020).

\section{4.compressive Strength (Ucs)}

The UCS of the samples is shown in Fig. 5. The control mix in the experiment had a 28-day UCS of $448 \mathrm{Kg} / \mathrm{Cm} 2$, but a $2 \%$ addition of shredded HPPM by volume produced the best results. In UCS to the control mix study, UCS increased steadily between $1 \%$ and $1.5 \%$ before falling marginally at $2.5 \%$. In comparison to the control sample, volume increments of $0.5 \%, 1 \%, 1.5 \%$, and $2 \%$ resulted in sample increases of $8.82,11.05,13.68$, and $9.40 \%$, respectively (Fig. 5). As a result, the findings show that incorporating HPPM into concrete had a significant impact on the UCS of the mixture. Xu et al., 2020, reported similar results in UCS, where the addition of different plastic fibers boosted UCS to the point where it began to fall. The improvement in UCS with the additional content of polypropylene fibres may be related to the fiber's crack restriction effect, as demonstrated in earlier investigations (Nili and 
Afroughsabet, 2010). According to the study by Mohammadhosseini et al., the declining trend at $2.5 \%$ could be owing to the presence of voids at $2.5 \%$ and the existence of weakening interfacial connections between the cut-up HPPM and the cement (2017).

When the fiber dosage was raised from $0 \%$ to $3 \%$, the UCS increased by $6 \%$ (Ravinder et al 2019). In other circumstances, such as (Ahmed et al 2020), fc rose until a specified fiber content value was reached and subsequently reduced. This could be due to poor workability induced by too many fibers and an increase in air content (Gencel et al 3011) and porosity (El-Newihy et al 2018).

The addition of HPPM to the mixtures, on the other hand, considerably modified the concrete's failure mode from brittle to ductile, as seen in Fig. 6 . The specimens did not crush because of the bridging effect of the HPPM fibers, and they maintained their integrity until the completion of the test. It was discovered that mixtures containing HPPM had lower compressive strength at an early age, but that after a longer period of curing, they had a higher compressive strength. This suggests that the bridging imacte of fiber can improve UCS of the concrete over time.

\subsection{Nondestructive Wave Velocity (Pv)}

At the age of 28 days, an ultrasonic test was performed on water saturated cubic concrete specimens of $150 \mathrm{~mm}$ to assess the number of internal pores in the specimens. This non-destructive test uses reflected waves that have radiated between probes to assess the permeability of a specimen, according to ASTM C597. The test was performed by crossing the two faces of the specimen with the instrument's two probes. The PV test is a nondestructive method for determining concrete's consistency and efficiency. Concrete cracks and pores are also referred to as PV (Ahmmad, et al., 2016). Non-destructive testing is a good way to assess the quality of concrete. The PV test's effects are depicted in Fig. 7a. PV grew consistently as HPPM content by volume climbed until the volume crossed $2.0 \%$, after which it declined marginally to $2.5 \%$, as seen in the data. Similarly, to UCS, the HPPM material with a volume of $2.0 \%$ produces the best results. According to Sims et al., (2019) and Khatib et al., (2019), concrete with a PV result more than $4500 \mathrm{~m} / \mathrm{s}$ is considered very good to outstanding concrete with a high-quality rating. The quality of the concrete fell once more at the $2.5 \%$ volume mark when compared to the control specimen for the experiment; nonetheless, it should be noted that the quality of the concrete improved in all mix designs, signifying beneficial features. According to Yap et al., (2013), good quality concrete has no substantial voids or cracks in the ranges mentioned; consequently, as proven in research by Shen et al., (2020), the usage of shredded face masks reduced the amount of microcracks in the concrete, thereby enhancing the overall quality of the concrete. No voids or cracks can jeopardize the structural integrity of the concrete within the above-mentioned limit. Due to an increase in void content and hence porosity with increased fiber, PV values tend to drop beyond a fibere composition of $2.5 \%$. According to BIS, the UPV measurements range between 3.8 and $4.04 \mathrm{Km} / \mathrm{sec}$, indicating that the concrete quality is good (IS 13311-1) (1992). HPPM was added to the equation, which increased the UPV values up to a particular volume fraction. However, as expected, increased HPPM stripes content resulted in lower UPV values. 
This decrease in change of velocity is thought to be owing to the existence of voids and microcracks in the concrete specimens, which reduced homogeneity at higher fiber volume fractions. For specimens containing HPPM at any \%, UPV values ranging from 4200 to $4600 \mathrm{~m} / \mathrm{s}$ were discovered, and it was regarded as good quality concrete.

The values of ultrasonic pulse velocity have been shown to be connected to their matching cube compressive strength. The relationship between UCS and UPV values of concrete mixtures including HPPM fiber have a strong relationship, as seen in Fig. 7b. A power regression method was used to correlate the experimental results, with an $\mathrm{R}^{2}$ of 0.872 for all samples, indicating a high level of confidence in the association.

\subsection{Sorptivity}

The findings of the (S) are shown in Fig. 8. When fiber concretes are compared to ordinary concrete, the (S), which is a measure of concrete durability, is lower. It's possible that the loss of connection in the pore space is caused by HPPM fibers filling porosity (Ramezanianpour et al 2013). The minimum (S) for $2 \%$ HPPM is 2.55(106) $(\mathrm{m} / \mathrm{s})$, whereas the maximum value for $2.5 \%$ HPPM is $3.46(\mathrm{~m} / \mathrm{s})$. Furthermore, every HPPM concrete has a lower (S) than the control mix, despite the fact that the high value for $2.5 \%$ HPPM is similar to a mix with a lot of porosity. This result demonstrates a considerable reduction in capillary ( $\mathrm{n}$ ) and inner conductivity of pores when HPPM fibers are used, and it confirms all of the other durability findings in this study.

\subsection{The Flexural Strength}

The FS of UCS and PV follows the similar pattern, with a rise up to $2 \%$ HPPM fibre content and then a reduction as the number of fibres increases. The results shown in this graph show that, similar to tensile strength, concrete flexure strength increased as the HPPM concentration increased. In comparison to the control mix, specimens with HPPM of $0.5 \%, 1 \%, 1.5 \%, 2 \%$, and $2.5 \%$ had FS of $17.8 \%, 24 \%, 27.5 \%$, $33.4 \%$, and $1.6 \%$, respectively. Furthermore, HPPM played a vital role in the development of FS, particularly after a longer duration of water curing. The overall effect of HPPM appears to be geared toward increasing FS, as evidenced by a $33.4 \%$ increase in flexural strength in concrete with $2.0 \%$ of HPPM. The drop in FS values as fiber content increases can be due to the fact that voids in the matrix grow as $2.5 \%$ HPPM fibres are added to the matrix. As a result of applying HPPM to sustainable concrete, the sample's FS was considerably boosted. As a result, further FS enhancements may be accomplished by introducing HPPM with an optimized geometric shape to create better concrete FS. The adoption of mechanically enhanced fibers with increased bond strength should result in more resilient structural concrete capable of producing bigger residual capacities as a result of developments in recycled HPPM processing.

The fibers intersecting the cracks in the tension zone of the specimens caused the rise in FS. HPPM fibers flex to hold the crack face separation, offering a larger energy absorption capacity and stress relaxing the 
micro-cracked area adjacent to the crack tip (Fig. 9a, b). Increased fiber content, on the other hand, resulted in reduced FS. This issue could be caused by the concrete's decreased workability at larger volume fractions in the combinations. The recorded FS of prismatic beams are shown in Fig. 9c.

\subsection{Impact Strength}

In terms of the number of blows required to cause the concrete specimen to collapse, the IMs of concrete was investigated for different volume fractions of HPPM fiber. PPF improves the impact resistance of concrete (Feng et al 2018). The addition of just $1 \%$ micro PPF increased the number of blows till failure by nearly thrice (Widodo 2012). The number of blows at first crack was assessed to be 76, 35, 546, 654, 987, and 698 percent for 0 percent, $0.5 \%, 1 \%, 1.5 \%, 2 \%$, and $2.5 \%$ of HPPM, respectively, when HPPM was added to concrete mixtures. Furthermore, with $0 \%, 0.5 \%, 1 \%, 1.5 \%, 2 \%$, and $2.5 \%$ of HPPM, the number of strikes required to destroy the sample increased 3.0, 3.3, and 4.8 times, respectively (Fig. 10). These findings are consistent with (Jain et al 2011), which found that the number of blows for failure increased from 76 (100\%) for ordinary concrete to 355 (367.105\%), 546 (618.421\%), 654 (760.526\%) 987(1198.68\%), and 689 (818.421\%) for concrete with HPPM fibers equal to $0 \%, 0.5 \%, 1 \%, 1.5 \%, 2 \%$, and $2.5 \%$, respectively, for concrete with HPPM fibers equal to mix control (Fig. 10).

\subsection{Spalling resistance}

Furthermore, when compared to concrete without fibers, the proportion of spalling for PPFRC is lower (Broda 2016). It is the outcome of the advancement of fire protection. HPPM melts at 160 degrees Celsius, while spalling occurs at 190 degrees Celsius (Olgun, M., 2013). As a result, as the fibers melt, empty channels emerge and a new pathway for gas to escape is generated. At the same time, it lowers the internal pore pressure. These findings have also been confirmed in publications by Kalifa et al. (2020), Algourdin et al. (2020), and others (2020). Finally, HPPM considerably improves the fire resistance of concrete.

\subsection{Abrasion Resistance}

It's worth noting that using HPPM fibers improves concrete's abrasion resistance. Horszczaruk (2012) demonstrated that after including $0.9 \mathrm{~kg} / \mathrm{m} 3$ of fibers, the mean depth of wear for HPPM fell from 29 to $42 \%$ as compared to plain concrete. The increase in abrasion resistance for concretes containing fibrillated $0 \%, 0.5 \%, 1 \%, 1.5 \%, 2 \%$, and $2.5 \%$ HPPM varied from $6.4 \%, 5.7 \%, 4.9 \%, 3.7 \%$, and $4.6 \%$, depending on the water to cement ratio (Grdic et al 2012).

This phenomenon can be explained by the fact that incorporating HPPM fibers into concrete inhibits the creation of cracks and effectively diminishes the concrete's intrinsic cracking tendency. Furthermore, the pore blocking effect of HPPM fibers causes the pore structures in hardened concrete to become more 
detached, resulting in less capillary porosity and lower water penetration of the concrete. In addition, HPPM's abrasion resistant strength is improved. On the resistance to abrasion damage, HPPM fibers outperform control concrete (Fig.11).

\subsection{Water absorption and porosity}

The resistance of concrete to the intrusion of hostile ions is another important aspect that influences its durability. The porosity of concrete is indirectly represented by its absorption characteristics, which also provide useful information regarding the permeable pore volume within the concrete and the connectivity between these pores. Ozbakkaloglu and Afroughsabet (2015). The percentage of Sw is a measure of pore volume or ( $\mathrm{n}$ ) of concrete after hardening, and it is one of the fundamental factors of concrete durability.

When it comes to water absorption, many studies show that HPPM absorbs less water than plain concrete (Li and Liu 2020). According to Afroughsabet and Ozbakkaloglu (2015), regular concrete absorbs $1.52 \%$ of water, but concretes containing 1.5, 3.0, and $4.5 \%$ PPF absorb 39, 46, and $49 \%$ of water, respectively. Similarly, in (Behfarnia, Behravan 2014), the water absorption was reduced by roughly $45 \%$, from $2.481 \%$ to $1.366 \%$. PPFRC absorbed $24.7 \%$ less water than concrete without fibers in tests (Bolat et al 2014). This could be due to the fibers' action limiting the number of cracks to a minimum. Fibers, on the other hand, have been shown in some tests to have a negative impact on absorbability.

The findings show that injecting HPPM into concrete reduced concrete's Sw significantly. When compared to the respective values obtained from control concrete mixes, water absorptions of concrete mixes with 0 $\% 0.5 \%, 1 \%, 1.5 \%, 2 \%$, and $2.5 \%$ HPPM decreased by $25 \%$ and $36 \%$, respectively. The results of polypropylene HPPM fiber-reinforced concretes show that HPPM fibers have a favorable effect on reducing concrete water absorption. As shown in Fig.12 a, increased fiber content resulted in a greater reduction in water absorption. As a result, among all HPPM fiber-reinforced concretes evaluated in this study, the combination containing 2\% HPPM fiber had the lowest water absorption. Adding fibers to concrete provides a variety of advantages, but it also causes the thickness of the transition zone to rise in hybrid fiber-reinforced concretes.

The influence of HPPM on porosity cannot be clearly measured, as seen in Fig. 12 b. Workability is influenced by a number of factors, one of which being the distribution of fibers within the mixture and the level of porosity. There have been studies that show that when the fiber dosage increases, the porosity increases (Fallah and Nematzadeh 2016). Porosity can decrease with the addition of fibers confined to a lower amount, then increase again with bigger fiber additions, as shown in (Ismail, M. Ramli 2016). The porosity of concrete with $0 \%, 0.5 \%, 1 \%, 1.5 \%, 2 \%$, and $2.5 \%$ HPPM varied between $4.9 \%, 4.3 \%, 5.2 \%$, $3.6 \%, 4.3 \%$, and $5.5 \%$ in the current study. A summary of how HPPM fiber incorporation affects concrete porosity (Fig.12 b). The findings of this study show that adding more than $2.5 \%$ of the HPPM fibers to concrete results in increased transition zone thickness and (n), and hence higher Sw. The increased 
porosity could be due to poor compaction, which could lead to more micro-cracks, unrestrained fibers, and cracks, as well as poor fiber-matrix bonding (Mohammadhosseini, and Yatim 2017).

\subsection{Water penetration and permeability}

Because of the pore blocking action of HPPM fibers, all water penetration depths for HPPM are lower than for control mix. The findings support the accuracy of HPPM readings.

The specimen with $2 \%$ HPPM fiber content has a minimum depth of penetration of $7.4 \mathrm{~mm}$, which is $38.33 \%$ less than the control mix. The drop in HPPM depth of water penetration and then increase (11.6 at $2.5 \%$ ) could be attributable to an increase in " $n$ " as the HPPM fiber content increases. In fact, the $2 \%$ decrease in water depth is most likely attributable to pore blockage and decreased capillary porosity. This result backs up the results of the other durability tests presented in this article. Figure 13 shows the findings depth of water penetration at the age of 28 days.

In addition, the impact of HPPM fibers on permeability is not well understood. In their study, Islam and Gupta (2016) found that adding PPF to concrete increases both water and gas permeability. Hager et al. reported a similar finding in their paper (2019). Many researches, on the other hand, discovered that fibers have a favorable effect on permeability. According to Zhang and Li (2013), adding PPF to concrete reduced the duration of water permeability. Similarly, samples with fibers demonstrated poorer permeability than samples without them in (Kakooei et al 2012). There have also been studies that show that permeability declines as the volume of fibers grows up to a certain point, then increases and sometimes exceeds that of plain concrete (Flores Medina et al 2015). This is usually due to a lack of workability and an excessive amount of fibers in the mixture.

The presence of HPPM fibers in the concrete reduces the likelihood of the concrete to break by limiting the formation of cracks. Fibers also cause the pore structures in hardened concrete to become more separated, resulting in lower capillary porosity and concrete water penetration.

\section{Role Of Stripes In Pore Blocking And Strength Improvements 5.1. Microstructure analysis}

The microstructure of HPPM fiber $r$ with $0.5 \%, 1 \%, 1.5 \%, 2 \%$, and $2.5 \%$ volume fraction of HPPM fiber was examined using SEM to evaluate the bond characteristic of the combination. Figure 14a, b depicts the HPPM fiber-matrix interface of a concrete composite including HPPM fibers, as well as fiber bridging following fracture. The results of compressive and flexural tests on concrete incorporating HPPM fiber show that the fiber-matrix interface is good and that the fiber-matrix bond is good. 
Another fault in concrete is that it breaks almost immediately after it is poured and before it has fully set. These fissures are a key source of concrete weakness, especially in large-scale worksite applications, causing fracture and failure as well as a general lack of resilience (Sivakumar and Santhanam, 2007a). Traditional reinforcing, as well as, to a lesser extent, the use of a suitable amount of particular fibers, will assist in overcoming the tension weakness (Ahmed et al., 2006). The microstructure of HPPM concrete with a $2 \%$ volume fraction of HPPM was investigated using SEM to assess the bond characteristic of HPPM in the combination. The microstructure at $0.5 \%, 1 \%$, and $1.5 \%$ of HPPM surface and hydrated cement matrix after the fracture of concrete specimen is shown in Figs. 14 (b, c, d). The surface of the HPPM is coated with densely hydrated cement matrix, as seen in Figs. 14 (b, c, and d). This event shows that HPPM and the wet cement matrix have formed a strong connection.

The HPPM and cement matrix have a strong interfacial connection, as seen in Fig. 14 (e). This bonding was important in reducing the size and number of cracks, which led to a $2 \%$ increase in HPPM strength. The bridging activity of fibers, via which the bridging fibers partially transferred the stress across the crack, could also account for the improved flexural performance of concrete containing HPPM. Similar findings were made by Nili and Afroughsabet (2010), who discovered that adding polypropylene to concrete increased its flexural strength substantially.

At $2 \%$ HPPM fibre, the greatest compressive strength values were attained. The highest UCS increase measured at $1.5 \%$ and $2 \%$ HPPM is $13.6 \%$ and $9.40 \%$, respectively. As a result, it is reasonable to conclude that stripes have a significant impact on compressive strength values. According to the findings, HPPM stripes have a considerable impact on UCS values when compared to control concrete. The great fineness and variable length of fibers in staple HPPM stripes form a network that works as a bridge, preventing the micro fracture from spreading further. When the HPPM stripes level is higher (2.5\%), however, the fibre stripes is dispersed unevenly in concrete due to poor workability and mixing. As a result, these fiber masses collected to generate weaker places (Fig. 14f)

After the flexure test, the fibres operate as a bridging element, effectively transferring the load from the matrix to the HPPM fibres, allowing them to take on the additional load, resulting in an increase in UCS and FS when compared to control concrete. The size and shape of the polypropylene fibres affect the increase in flexure strength of concrete. It can also be seen that, as a result of the lower effective w/c ratio, the splitting tensile and FS values are relatively high, with $17.8 \%, 24 \%, 27.5 \%, 33.4 \%$, and $1.6 \%$ increases in FS at $0.5 \%, 1 \%, 1.5 \%, 2 \%$, and $2.5 \% \mathrm{HPPM}$, respectively, when compared to control samples. In a scattered stripes cement matrix, stress concentrations are not uniform along the length of the fibre.

Combination of HPPM stripes and fibers as a factor in improving FS, especially in older people. HPPM stripes flex to keep the fracture face apart, offering a larger energy absorption capacity while also stress relaxing the microcracked area adjacent to the crack tip. However, a higher fiber content ( $2.5 \%$ HPPM) resulted in a reduction in FS (Fig. 14f). This issue could be caused by the concrete's decreased workability at larger volume fractions in the combinations. Inadequate compaction, more micro-cracks, uncontrolled 
fibers and cracks, and poor fiber-matrix bonding could all contribute to the increased permeability and porosity. HPPM acts as a three-dimensional reinforcement, bridging cracks and preventing them from growing and enlarging (Yang et al 2020). It is important to note that cracks are not detrimental to the construction or serviceability if they do not surpass a particular size. When concrete transitions from a plastic to a solid state, and the concrete's Young's modulus exceeds the Young's modulus of the fibers, micro HPPMs are no longer thought to play a significant role. Furthermore, in (Sivakumar, M. Santhanam 2007 b) the cracking area in concrete with $0.5 \%$ PPF was reduced by $99 \%$. PPF prevents cracks from forming not only against plastic shrinkage, but also against drying shrinkage (Sivakumar, M. Santhanam 2007b, Yinet et al., 2015, Zych et al., 2016, and Krasodomski et al., 2016).

However, in Fig. 14f, 2.5 \% HPPM has higher porosity, causing the specimen to be non-homogeneous. Furthermore, HPPM Fibers have a bridging effect, which could lead to increased compressive and flexural strengths. Less permeability and capillary porosity do, in reality, have a close relationship. It may be deduced that the voids in $2.5 \%$ HPPM, which are more than those in $2 \%$, are caused by HPPM fibers trapping air in the mixture. Furthermore, the HPPM stripes and fibres can be seen as a binder all over the fibers and aggregates in this micrograph, potentially causing pore blockage and decreased permeability. Less permeability and capillary porosity do, in reality, have a close relationship. It may be deduced that the voids in $2.5 \%$ HPPM, which are more than those in $2 \%$ HPPM, are caused by fibers that have trapped air in the mixture.

\subsection{Geometry And Crack-strengthening Mechanisms}

Some academics have recently emphasized the impact of fissures on concrete permeability (2009). Wang et al. (1997) investigated the effect of fracture width on concrete permeability in an experimental setting. Shin et al. (2017) studied the impacts of concrete permeability on fracture type, crack width, and water heads. Yang et al. (2018) used X-ray CT to monitor the water transport parameters of cracked concretes and indicated that fracture morphology and tortuosity should be studied in future research.

The main role of HPPM in the concrete construction is depicted in Fig. 15. As can be seen, stresses arising from plastic shrinkage exceed the concrete strength in the initial hours of its age, when both strength and Young's modulus are quite low. Shrinkage cracks form as a result of this. The formation of cracks is slowed by a high number of equally dispersed HPPM, which reduce crack width by two orders of magnitude (Yin et al. 2015). It is important to note that cracks are not detrimental to the construction or serviceability if they do not surpass a particular size. When concrete transitions from a plastic to a solid state, and the concrete's Young's modulus exceeds the Young's modulus of the fibers, micro HPPMs are no longer thought to play a significant role. Concrete samples with no fibers had a breaking area of 1743 $\mathrm{mm}^{2}$ in the study (Cao et. al., 2020), while those containing $0.5 \%$ and $1.0 \%$ PPF had cracking areas of 992 and $99 \mathrm{~mm}^{2}$, respectively. The presence of HPPM increased the drying shrinkage resistance of concrete, according to the findings of this study. 
The addition of macro HPPM fibers can change the fracture shape, based on the physical and mechanical data above. The behavior could be attributed to the macro polypropylene fibers, which are scattered stochastically in the matrix, preventing the matrix fracture from propagating without stretching and deboning the fibers, resulting in a deviated crack extension route. When comparing HPPM fiber specimens to control concrete samples, specimens with a fiber dosage of $2.5 \%$ showed the most significant increase in crack morphology.

The use of fibers from various raw materials is efficient in controlling crack formation on exposed concrete surfaces caused by early age drying shrinkage (Shi et al 2020). Because they restricted the motions of micro level in concretes by bridging and stitching the fine fractures, PPF in concrete decreases drying shrinkage and early cracking (Yin et al 2015). The impact of HPPM on matrix fracture behavior can be separated into two categories. To begin with, the addition of HPPM fiber reduces the maximum stress as well as the elastic modulus of the mixes. Second, after the grain-bridging crack face breaks, stress can be transferred via the cracks via the intersection of fibers and cracks. Crack bridging activity results in increased ductility in HPPM fiber reinforced concrete (Fig. 15).

\subsection{Eco-friendly and economic feasibility of HPPM}

In today's construction business, the issue of susceptibility and environmentally friendly materials is hotly debated. $\mathrm{CO}_{2}$ concentrations in the environment have raised by $50 \%$ in the twenty-first century (Kumar Mehta and Burrows, 2001). Concrete manufacturing accounts for 2-3\% of annual energy demand and 8-9\% of total $\mathrm{CO}_{2}$ emissions in the atmosphere (Monteiro, et al 2016). As a result, the construction industry now faces a new challenge: manufacturing concrete structures that meet environmental standards while also being more durable. Protecting steel bars from corrosion and sulfate attack improves the longevity of reinforced concrete, allowing water and ions to penetrate through cracks and pores (Kumar Mehta and Burrows 2001). Plastic shrinkage at an early age is widely recognized as one of the leading causes of concrete cracks. As a result, the idea of HPPM fiber inclusion appears to be quite useful in terms of long-term development. Ali et al. (2020) report a comparative research of plain concrete and concretes containing various kinds of fibers, including steel, glass, and PP. It was discovered that the manufacture of PPF produced 30 and $9 \%$ less $\mathrm{CO}_{2}$ than steel and glass fibers, respectively. The environmental and economic issues of pavements made from the various concretes described above were evaluated. In addition, depending on the fiber dose, carbon emissions per $\mathrm{m}^{2}$ of pavement were reduced by $13-18 \%$. The thickness of concrete pavement was lowered by $18 \%$ in another study (Garg and Garg 2020) thanks to the use of PPF. Inappropriate management of spent HPPM is another plausible pathway for COVID-19 transmission. As a reason, the present work encourages scientists to express their concerns to governments at all levels about the significance of implementing suitable solid waste management measures, such as HPPM, to prevent the spread of the novel coronavirus. With $50 \%$ of the population, Saudi Arabia must be the most populous country in the Arabian Peninsula. Coronavirus Cases: 417,363 . There have been 6,957 deaths. A total of 375,831 dollars was recovered (www.worldometers.info). As previously stated, the primary application of fiber reinforced concrete is the 
construction of structural elements. The prospect of employing such concretes to build architectural shapes is considered less frequently. Public spaces are one of the field's applications in architecture. Public open spaces are one of the most important aspects of city life (Gehl 2013), and their

attractiveness has an impact on how people view the city. Furthermore, as a result of them, cities are seen as pleasant and inviting to people. HPPM stripes can be used to produce architectural shapes in public spaces, such as decorative pavements in scientific centers, shopping centers, rest zoons, promenades, zoos and gardens, bus stations, parking area, ferry terminals, feck rocks, beaches area, landscapes, door surrounds, and skateparks. Finally, some habits of materials utilized in space should be taken into consideration.

\section{Conclusion}

The main function of HPPM stripes in the concrete construction is to reduce plastic shrinkage cracks. Mix change improves many characteristics of HPPM fiber reinforced concrete. However, certain qualities have a neutral effect or are difficult to assess. It's also worth noting that the conclusion that higher HPPM fiber content equals better characteristics isn't always correct and an excessive amount of fibers can cause substantial deterioration. Polypropylene fibers, for example, improve the material's characteristics up to a specific dosage, which, if exceeded, has detrimental consequences. When determining the HPPM ideal fiber content, it is critical to consider the mixture composition and fiber qualities. HPPM fiber reinforced concrete applications in public open places are a promising field. Because they are subjected to adverse environmental conditions, damages, abrasion of surface, and vandalism, using concrete with enhanced qualities is definitely advantageous.

In made sustainable concrete, various percentages of iron waste $(0,0.5,1,1.5,2.0$, and $2.5 \%)$ are employed. Slump, compressive strength, flexural strength, abrasion resistance, impact resistance, sorptivity, spalling test, water absorption, porosity, water penetration, permeability, and UPV were all investigated by the researchers. Based on the results of the experiment, the following conclusions can be drawn:

When HPPM fibers are added to the concrete mixture, it reduces the new concrete's workability and has the potential to improve some of the mechanical qualities of the concrete when utilized in small amounts.

When compared to the control mix, HPPM improved the overall quality of the concrete because the fibers were more evenly spread, resulting in higher compressive and flexural strengths. Because they restricted the movements of micro level in concretes by bridging and sewing the fine cracks, HPPM in concrete decreases drying shrinkage and early cracking. The mixture with $2 \%$ of the HPPM fiber content yields the highest compressive and flexural strengths.

The findings of the XRD test show that after introducing PP fibers, neither $\mathrm{Ca}(\mathrm{CO})_{3}$ nor $\mathrm{Ca}(\mathrm{OH})_{2}$ have altered appreciably. This incident could demonstrate that fibers are incapable of participating in chemical 
reactions. Aside from that, the convex shape of the analyzer could indicate the presence of amorphous materials. The presence of fibers causes a considerable change in the cracking pattern of concrete. While unreinforced concrete forms wide crack widths and long cracks, the inclusion of fibers reduced the crack width opening, cracked area, and crack propagation through the bridging activity of fibers. Crack networks become less connected as a result of the fibers addition.

Water absorption in hardened concrete is reduced when HPPM stripes and fibers are added in low volume fractions to the concrete mixture separately. Furthermore, using HPPM fibers in small volume fractions reduces the porosity of concrete specimens. Among all the concrete specimens, the concrete containing 2 $\%$ HPPM fibers has the lowest water absorption and porosity percentage. Regardless of the volume concentration of HPPM, all concrete mixes are subjected to the same high standard of excellent quality, strong concrete, and structural strength.

Micro fractures propagate along the concrete with HPPM, according to concrete microstructure study. As demonstrated in SEM pictures, HPPM fibers (2\%) play a significant role in fracture bridging. However, when the volume percentage of fibers is higher (2.5\% of HPPM), voids form and grow between the cement paste and the fibre, reducing the concrete's strength qualities. As a result, the HPPM can be utilized to make sustainable concrete and produce a clean, healthy environment as a building material. In addition, the HPPM fibers employed in this study were classified as short or discontinuous fibers, which could lead to increased UCS and FS and abrasion resistance.

\section{Abbreviation}

\begin{tabular}{ll} 
PPs & Polypropylene stripes \\
\hline HPPM & Healthy Personal Protective Materials \\
\hline FM & Single-Used Face Mask \\
\hline UCS & Uniaxial Compressive Strength \\
\hline FS & Flexural Strength \\
\hline PV & Ultrasonic Pulse Velocity \\
\hline SEM & Scanning Electron Microscope \\
\hline XRD & X-ray diffraction patterns \\
\hline n & Porosity \\
\hline Sw & Water absorption \\
\hline IMs & Impact strength \\
\hline AbR & Abrasion resistance \\
\hline S & Sorptivity coefficients
\end{tabular}

Page 19/40 


\section{Declarations}

\section{Data availability statement}

The data that support the findings of this study are available from the corresponding author upon reason

\section{Author contribution}

The author (Abd El Aal) has the sole responsibility for the study conception and design, data collection, analysis and interpretation of results, and manuscript preparation.

\section{Funding Non}

Ethics approval and consent to participate Not applicable.

Consent for publication Not applicable.

Conflict of interest The author declares no competing interests.

\section{References}

1. A. El-Newihy, P. Azarsa, R. Gupta, A. Biparva, Effect of polypropylene fibers on self-healing and dynamic modulus of elasticity recovery of fiber reinforced concrete, Fibers 6 (2018) 9, doi:http://dx.doi.org/10.3390/fib6010009.

2. A. Mohajerani, S.-Q. Hui, M. Mirzababaei, A. Arulrajah, S. Horpibulsuk, A. Abdul Kadir, M.T. Rahman, F. Maghool, Amazing types, properties, and applications of fibres in construction materials, Materials 12 (2019) 2513, doi:http://dx.doi.org/10.3390/ma12162513.

3. A.A. Ramezanianpour, M. Esmaeili, S.A. Ghahari, M.H. Najafı Laboratory study on the effect of polypropylene fiber on durability, and physical and mechanical characteristic of concrete for application in sleepers. Construction and Building Materials 44 (2013) 411418. http://dx.doi.org/10.1016/j.conbuildmat.2013.02.076.

4. Ahmed, T.W. Ali, A.A.MZidan: . R.S. Properties of high strength polypropylene fiber concrete containing recycled aggregate Constr. Build. Mater., 241 (2020), p. 118010, 10.1016/j.conbuildmat.2020.118010

5. Ahmmad, R. Jumaat, M.Z. Alengaram, U.J. Bahri, S. Rehman, M.A. Hashim H.B. Performance evaluation of palm oil clinker as coarse aggregate in high strength lightweight concrete J. Cleaner Prod., 112 (2016), pp. 566-574

6. Akber Abbasi, S. Khalil, A.B. Arslan M. Extensive use of face masks during COVID-19 pandemic: (micro-)plastic pollution and potential health concerns in the Arabian Peninsula Saudi J. Biol. Sci. (2020), 10.1016/j.sjbs.2020.09.054

7. Al-Hadithi, A., Hilal, N., 2016. The possibility of enhancing some properties of self- compacting concrete by adding waste plastic fibers. Journal of Building Engineering 8, $20 \mathrm{e} 28$. 
8. Al-Hadithi, A., Noaman, A., Mosleh, W., 2019. Mechanical properties and impact behavior of PET fiber reinforced self-compacting concrete (SCC). Compos. Struct. 224, 111021

9. ASTM C1602 / C1602M-18, Standard Specification for Mixing Water Used in the Production of Hydraulic Cement Concrete, ASTM International, West Conshohocken, PA, 2018, www.astm.org

10. ASTM C192 / C192M-19, Standard Practice for Making and Curing Concrete Test Specimens in the Laboratory, ASTM International, West Conshohocken, PA, 2019, www.astm.org

11. ASTM C31 / C31M-21, Standard Practice for Making and Curing Concrete Test Specimens in the Field, ASTM International, West Conshohocken, PA, 2021, www.astm.org

12. ASTM C33 / C33M-18, Standard Specification for Concrete Aggregates, ASTM International, West Conshohocken, PA, 2018, www.astm.org

13. ASTM C39 / C39M-21, Standard Test Method for Compressive Strength of Cylindrical Concrete Specimens, ASTM International, West Conshohocken, PA, 2021, www.astm.org

14. ASTM C496 / C496M-17, Standard Test Method for Splitting Tensile Strength of Cylindrical Concrete Specimens, ASTM International, West Conshohocken, PA, 2017, www.astm.org

15. ASTM C597-16, Standard Test Method for Pulse Velocity Through Concrete, ASTM International, West Conshohocken, PA, 2016, www.astm.org

16. ASTM C78 / C78M-21, Standard Test Method for Flexural Strength of Concrete (Using Simple Beam with Third-Point Loading), ASTM International, West Conshohocken, PA, 2021, www.astm.org

17. ASTM D570-98(2018), Standard Test Method for Water Absorption of Plastics, ASTM International, West Conshohocken, PA, 2018, www.astm.org

18. ASTM D638-14, Standard Test Method for Tensile Properties of Plastics, ASTM International, West Conshohocken, PA, 2014, www.astm.org

19. ASTM D7138-16, Standard Test Method to Determine Melting Temperature of Synthetic Fibers, ASTM International, West Conshohocken, PA, 2016, www.astm.org

20. ASTM D792-20, Standard Test Methods for Density and Specific Gravity (Relative Density) of Plastics by Displacement, ASTM International, West Conshohocken, PA, 2020, www.astm.org

21. B. Ali, L.A. Qureshi, R. Kurda, Environmental and economic benefits of steel, glass, and polypropylene fiber reinforced cement composite application in jointed plain concrete pavement, Compos. Commun. 22 (2020) 100437, doi:http://dx.doi.org/10.1016/j.coco.2020.100437.

22. Behfarnia, K. Behravan, A. Application of high performance polypropylene fibers in concrete lining of water tunnels, Mater. Des. 55 (2014) 274-279, doi:http://dx.doi.org/10.1016/j.matdes.2013.09.075

23. Blazy $\mathrm{J}$ and Blazy R, Polypropylene fiber reinforced concrete and its application in creating architectural forms of public spaces. Case Studies in Construction Materials. Volume 14, June 2021, e00549. https://doi.org/10.1016/j.cscm.2021.e00549

24. BS EN 12390-8:2009 Testing hardened concrete. Depth of penetration of water under pressure.

25. Wagner, C. Villmann, B. Slowik, V. (2017), Water permeability of cracked strain hardening cementbased composites, Cem. Concr. Compos. 82 (2017) 234- 241, 
https://doi.org/10.1016/j.cemconcomp.2017.06.003.

26. Chou LH, Lu CK, Lee MT. Studies on improving PP fibers reinforced concrete. 1st International conference on civil engineering, architecture and building materials, CEABM 2011;250-253:67881.Constr. Build. Mater. 176 (2018) 652-664, https://doi.org/10.1016/ j.conbuildmat.2018.05.094.

27. D. Li, S. Liu (2020) Macro polypropylene fiber influences on crack geometry and water permeability of concrete Constr. Build. Mater., 231 (2020), p. 117128, 10.1016/j.conbuildmat.2019.117128

28. D. Li, S. Liu, Macro polypropylene fiber influences on crack geometry and water permeability of concrete, Constr. Build. Mater. 231 (2020) 117128, doi: http://dx.doi.org/10.1016/j.conbuildmat.2019.117128.

29. Das CS, Dey T, Dandapat R, et al. Performance evaluation of polypropylene fibre reinforced recycled aggregate concrete. Constr Build Mater. 2018;189: 649-659.

30. Dev. 3 (2012) 3008, doi:http://dx.doi.org/10.6088/ijcser.201203013008.

31. Doan H.N. (2020)Medical face masks can be reused with microwave method: expert https://vietnamnews.vn/society/654072/medical-face-masks-can-be-reused-with-microwavemethod-expert.html (2020)

32. García-Taengua, E. Arango, S. Martí-Vargas, J.R. Serna, P. (2014) Flexural creep of steel fiber reinforced concrete in the cracked state, Constr. Build. Mater. 65 (2014) 321-329, doi:http://dx.doi.org/10.1016/j.conbuildmat.2014.04.139.

33. Horszczaruk, E. (2012) Abrasion resistance of high-performance hydraulic concrete with polypropylene fibers, Tribologia 1 (2012) 63-72.

34. F. Shi, T.M. Pham, H. Hao, Y. Hao, Post-cracking behaviour of basalt and macro polypropylene hybrid fibre reinforced concrete with different compressive strengths, Constr. Build. Mater. 262 (2020) 120108, doi:http://dx.doi.org/10.1016/j.conbuildmat.2020.120108.

35. G. Rastiello, C. Boulay, S.D. Pont, et al., Real-time water permeability evolution of a localized crack in concrete under loading, Cem. Concr. Res. 56 (2) (2014) 20-28, https://doi.org/10.1016/j.cemconres.2013.09.010.

36. G. Rastiello, S. Dal Pont, J.L. Tailhan, et al., On the threshold crack opening effect on the intrinsic permeability of localized macro-cracks in concrete samples under Brazilian test conditions, Mech. Res. Commun. 90 (2018) 52-58, https:// doi.org/10.1016/j.mechrescom.2018.04.008.

37. H. Bolat, O. Şimşek, M. Çullu, G. Durmuş, Ö. Can, The effects of macro synthetic fiber reinforcement use on physical and mechanical properties of concrete, Compos. Part B Eng. 61 (2014) 191-198, doi:http://dx.doi.org/10.1016/j.compositesb.2014.01.043.

38. H.R. Tavakoli, O.L. Omran, M.F. Shiade, S.S. Kutanaei, Prediction of combined effects of fibers and nanosilica on the mechanical properties of self-compacting concrete using artificial neural network, Lat. Am. J. Solids Struct. 11 (2014) 1906-1923, doi:http://dx.doi.org/10.1590/S167978252014001100002.

39. Hamzavi, I.H., Lyons, A.B., Kohli, I., Narla, S., Parks-Miller, A., Gelfand, J.M., Lim, H.W., Ozog, D., 2020. Ultraviolet germicidal irradiation: possible method for respirator disinfection to facilitate reuse during 
COVID-19 pandemic. J. Am. Acad. Dermat. https://doi.org/10.1016/j.jaad.2020.03.085

40. I. Hager, K. Mróz, T. Tracz, Contribution of polypropylene fibres melting to permeability change in heated concrete - the fibre amount and length effect, IOP Conf. Ser. Mater. Sci. Eng. 706 (2019) 012009, doi:http://dx.doi.org/10.1088/1757-899X/706/1/012009.

41. IS 13311 (Part I): 1992 Non-Destructive Testing of Concrete Methods of test (Ultrasonic Pulse Velocity) IS 13311 (Part II): 1992 Non-Destructive Testing of Concrete Methods of test (Rebound Hammer)

42. ISRM (2007) The Complete ISRM Suggested Methods for Rock Characterization, Testing and Monitoring: 1974-2006. Suggested Methods Prepared by the Commission on Testing Methods, International Society for Rock Mechanics, Compilation Arranged by the ISRM Turkish National Group Ankara, Turkey, $628 \mathrm{p}$.

43. Broda, J. (2016) Application of polypropylene fibrillated fibres for reinforcement of concrete and cement mortars, High Perform. Concr. Technol. Appl., InTech, 2016, pp. 189-205, doi:http://dx.doi.org/10.5772/64386.

44. J. Feng, W. Sun, H. Zhai, L. Wang, H. Dong, Q. Wu, Experimental study on hybrid effect evaluation of fiber reinforced concrete subjected to drop weight impacts, Materials. 11 (2018) 2563, doi:http://dx.doi.org/10.3390/ma11122563.

45. J. Gehl, Cities for People, Island press, 2013.

46. J. Rapoport, C.M. Aldea, S.P. Shah, et al., Permeability of cracked steel fiberreinforced concrete, J. Mater. Civ. Eng. 14 (4) (2002) 355-358, https://doi.org/ 10.1061/(ASCE)0899-1561(2002) 14:4(355).

47. J.G. Macgregor, Reinforced Concrete: Mechanics and Design, Prentice Hall, New Jersey, 1997.

48. Jiang, J.Q., 2018. Occurrence of microplastics and its pollution in the environment: A review. Sustainable Production and Consumption 13, 16-23.

49. K. Wang, D.C. Jansen, S.P. Shah, et al., Permeability study of cracked concrete, Cem. Concr. Res. 27 (3) (1997) 381-393, https://doi.org/10.1016/S0008-8846 (97)00031-8.

50. K.J. Shin, W. Bae, S.W. Choi, et al., Parameters influencing water permeability coefficient of cracked concrete specimens, Constr. Build. Mater. 151 (2017) 907-915, https://doi.org/10.1016/j.conbuildmat.2017.06.093.

51. Kampf, G., Todt, D., Pfaender, S., \& Steinmann, E. (2020). Persistence of coronaviruses on inanimate surfaces and their inactivation with biocidal agents. The Journal of hospital infection, 104(3), 246251. https://doi.org/10.1016/j.jhin.2020.01.022

52. Karahan, O. Atiş, C.D. The durability properties of polypropylene fiber reinforced fly ash concrete, Mater. Des. 32 (2011) 1044-1049, doi:http://dx.doi.org/10.1016/j.matdes.2010.07.011.

53. Kazemi, M., Hajforoush, M., Talebi, P.K., Daneshfar, M., Shokrgozar, A., Jahandari, S., Saberian, M., Li, J., 2020a. In-situ strength estimation of polypropylene fibre reinforced recycled aggregate concrete using Schmidt rebound hammer and point load test. Journal of Sustainable Cement-Based Materials 9 (5), $289 \mathrm{e} 306$. 
54. Kazemi, M., Li, J., Lahouti Harehdasht, S., Yousefieh, N., Jahandari, S., Saberian, M., 2020b. Nonlinear behaviour of concrete beams reinforced with GFRP and CFRP bars grouted in sleeves. Structure 23, 87e102.

55. Khatib, J.M., Herki, B.A., Elkordi, A., 2019. 7 - characteristics of concrete containing EPS. In: PACHECO-TORGAL, F., KHATIB, J., COLANGELO, F., TULADHAR, R. (Eds.), Use of Recycled Plastics in Eco-Efficient Concrete. Woodhead Publishing.

56. Knaze, P. Beno, P. The use of combined non-destructive testing methods to determine the compressive strength of concrete, Mater. Struct. 17 (3) (1984) 207-210.

57. L. Le, K. Li, Experimental investigation on transport properties of cement-based materials incorporating 2D crack networks, Transp. Porous Med. 122 (3) (2018) 647-671, https://doi.org/10.1007/s11242-018-1019-0.

58. M. Hoseini, V. Bindiganavile, N. Banthia, The effect of mechanical stress on permeability of concrete: a review, Cem. Concr. Compos. 31 (4) (2009) 213- 220, https://doi.org/10.1016/j.cemconcomp.2009.02.003.

59. M.G. Chorzepa, M. Masud, Performance of multiscale, including nanoscale, fibres in concrete, Emerg. Mater. Res. 6 (2017) 198-209, doi:http://dx.doi. org/10.1680/jemmr.16.00020.

60. M.H. Wan Ibrahim, S.A. Mangi, M.K. Burhanudin, M.B. Ridzuan, N. Jamaluddin, S. Shahidan, Y. Wong, S. Faisal, M.A. Fadzil, P.J. Ramadhansyah, S.S. Ayop, N.H. Othman, Compressive and flexural strength of concrete containing palm oil biomass clinker and polypropylene fibres, IOP Conf. Ser. Mater. Sci. Eng. 271 (2017) 012011, doi:http://dx.doi.org/10.1088/1757-899X/271/1/012011.

61. M.N. Soutsos, T.T. Le, A.P. Lampropoulos, Flexural performance of fibre reinforced concrete made with steel and synthetic fibres, Constr. Build. Mater. 36 (2012) 704-710, doi:http://dx.doi.org/10.1016/j.conbuildmat.2012.06.042.

62. Markovic, High-Performance Hybrid-Fibre Concrete, DUP Science DUP, Delft, 2006.

63. Mehta P, Monteiro Paulo. Concrete: microstructure, properties, and materials. McGraw-Hill Professional; 2005.

64. Mohajerani, S.-Q. Hui, M. Mirzababaei, A. Arulrajah, S. Horpibulsuk, A. Abdul Kadir, M.T. Rahman, F. Maghool, Amazing types, properties, and applications of fibres in construction materials, Materials 12 (2019) 2513, doi:http://dx.doi.org/10.3390/ma12162513.

65. Mohammadhosseini, H., Abdul Awal, A.S.M., Mohd Yatim, J.B., 2017. The impact resistance and mechanical properties of concrete reinforced with waste poly- propylene carpet fibres. Construct. Build. Mater. 143, 147e157.

66. Mohammadhosseini, H., Yatim, J.M. Evaluation of the Effective Mechanical Properties of Concrete Composites Using Industrial Waste Carpet Fiber. INAE Lett 2, 1-12 (2017). https://doi.org/10.1007/s41403-017-0016-x

67. Mukharjee, B.B. Barai, S.V. Influence of Nano-Silica on the properties of recycled aggregate concrete, Constr. Build. Mater. 55 (2014) 29-37. 
68. N. Algourdin, P. Pliya, A.-L. Beaucour, A. Simon, A. Noumowé, Influence of polypropylene and steel fibres on thermal spalling and physical-mechanical properties of concrete under different heating rates, Constr. Build. Mater. 259 (2020) 119690, doi:http://dx.doi.org/10.1016/j. conbuildmat.2020.119690.

69. N. Flores Medina, G. Barluenga, F. Hernández-Olivares, Combined effect of Polypropylene fibers and Silica Fume to improve the durability of concrete with natural Pozzolans blended cement, Constr. Build. Mater. 96 (2015) 556-566, doi:http://dx.doi.org/10.1016/j.conbuildmat.2015.08.050.

70. N. Ranjbar, M. Zhang Fiber-reinforced geopolymer composites: a review Cement Concr. Compos., 107 (2020), p. 103498

71. Neto, J.A.B., Gaylarde, C., Beech, I., Bastos, A.C., da Silva Quaresma, V. and de Carvalho, D.G., 2019. Microplastics and attached microorganisms in sediments of the Vitória bay estuarine system in SE Brazil. Ocean \& Coastal Management, 169, 247-253.

72. Nili M, Afroughsabet $V(2010)$ The effects of silica fume and polypropylene fibers on the impact resistance and mechanical properties of concrete. Constr Build Mater 24(6):927-933

73. Nzediegwu, C., Chang, S.X., 2020. Improper solid waste management increases potential for COVID19 spread in developing countries. Resour. Conserv. Recycl. 161, 104947. https://doi.org/10.1016/j.resconrec.2020.104947

74. O. Gencel, C. Ozel, W. Brostow, G. Martínez-Barrera, Mechanical properties of self-compacting concrete reinforced with polypropylene fibres, Mater. Res. Innov. 15 (2011) 216-225, doi:http://dx.doi.org/10.1179/143307511X13018917925900.

75. Olgun, M., 2013. Effects of polypropylene fiber inclusion on the strength and volume change characteristics of cement-fly ash stabilized clay soil. Geosynth. Int. 20 (4), 263e275.

76. P. Balaguru, H. Najm, High-performance fiber-reinforced concrete mixture proportions with high fiber volume fractions, ACI Mater. J. 101 (2004), doi: http://dx.doi.org/10.14359/13361.

77. P. Kalifa, G. Chéné, C. Gallé, High-temperature behaviour of HPC with polypropylene fibres - from spalling to microstructure, Cem. Concr. Res. 31 (2001) 1487-1499, doi:http://dx.doi.org/10.1016/S0008-8846(01)00596-8.

78. P. Kumar Mehta, R.W. Burrows, Building durable structures in the 21 st century, Indian Concr. J. 75 (2001) 437-443.

79. P. Zhang, Q.F. Li, Effect of polypropylene fiber on durability of concrete composite containing fly ash and silica fume, Compos. Part B Eng. 45 (2013) 1587-1594, doi:http://dx.doi.org/10.1016/j.compositesb.2012.10.006

80. P.J.M. Monteiro, S.A. Miller, A. Horvath, Towards sustainable concrete, Nat. Mater. 16 (2017) 698699, doi:http://dx.doi.org/10.1038/nmat4930.

81. Pesic, N., Zivanovic, S., Garcia, R., Papastergiou, P., 2016. Mechanical properties of concrete reinforced with recycled HDPE plastic fibres. Construct. Build. Mater. 115, 362e370.

82. Q. Cao, R. Wang, J. Jia, C. Zhou, Z. Lin, A comparative study of combined treatments for enhanced early-age cracking control of self-consolidating concrete, Constr. Build. Mater. 248 (2020) 118473, 
doi:http://dx.doi.org/10.1016/j.conbuildmat.2020.118473.

83. R. Garg, R. Garg, Performance evaluation of polypropylene fiber waste reinforced concrete in presence of silica fume, Mater. Today Proc. (2020) 6-13, doi:http://dx.doi.org/10.1016/j.matpr.2020.06.482.

84. R. Park, T. Paulay, Reinforced concrete structures, John Wiley \& Sons Inc, New York, 1975.

85. R. Ravinder, V. Kumar, C. Kumar, A. Prakash, P.V.V.S.S.R. Krishna, Strength characteristics of fibrous self curing concrete using super absorbent polymer, Natl. Conf. Recent Adv. Civ. Eng., (2019).

86. S. Fallah, M. Nematzadeh, Mechanical properties and durability of high-strength concrete containing macro-polymeric and polypropylene fibers with nano-silica and silica fume, Constr. Build. Mater. 132 (2017) 170-187, doi:http://dx.doi.org/10.1016/j.conbuildmat.2016.11.100.

87. S. Ismail, M. Ramli, Effects of adding fibre on strength and permeability of recycled aggregate concrete containing treated coarse RCA, Int. J. Civ. Environ. Eng. 8 (2014) 918-924.

88. S. Kakooei, H.M. Akil, M. Jamshidi, J. Rouhi, The effects of polypropylene fibers on the properties of reinforced concrete structures, Constr. Build. Mater. 27 (2012) 73-77, doi:http://dx.doi.org/10.1016/j.conbuildmat.2011.08.015.

89. S. Widodo, Fresh and hardened properties of polypropylene fiber added self-consolidating concrete, Int. J. Civ. Struct. Environ. Infrastruct. Eng. Res.

90. Ş. Yazici, G. Inan, V. Tabak, Effect of aspect ratio and volume fraction of steel fiber on the mechanical properties of SFRC, Constr. Build. Mater. 21 (2007) 1250-1253, doi:http://dx.doi.org/10.1016/j.conbuildmat.2006.05.025.

91. S. Yin, R. Tuladhar, F. Shi, M. Combe, T. Collister, N. Sivakugan, Use of macro plastic fibres in concrete: a review, Constr. Build. Mater. 93 (2015) 180-188, doi:http://dx.doi.org/10.1016/j.conbuildmat.2015.05.105.

92. S. Yin, R. Tuladhar, F. Shi, M. Combe, T. Collister, N. Sivakugan, Use of macro plastic fibres in concrete: a review, Constr. Build. Mater. 93 (2015) 180-188, doi:http://dx.doi.org/10.1016/j.conbuildmat.2015.05.105.

93. S.W. Tang, Y. Yao, C. Andrade, et al., Recent durability studies on concrete structure, Cem. Concr. Res. 78 (2015) 143-154, https://doi.org/10.1016/j. cemconres.2015.05.021.

94. Saberian, M. Li, J. Kilmartin-Lynch, S. Boroujeni M. (2021) Repurposing of COVID-19 single-use face masks for pavements base/subbase Sci. Total Environ., 769 (2021), p. 145527

95. Sadiqul Islam, G.M., Gupta, S.D., 2016. Evaluating plastic shrinkage and permeability of polypropylene fiber reinforced concrete. International Journal of Sustainable Built Environment 5, $345 \mathrm{e} 354$.

96. Shokrieh Mahmood M, Rahmat Meysam. On the reinforcement of concrete sleepers by composite materials. Compos Struct 2006; 76:326-37.

97. Simsek, B. Uygunoglu, T., Korucu, H., Kocakerim, M.M., 2019. Performance of dioctyl terephthalate concrete. In: PACHECO-TORGAL, F., KHATIB, J., COLANGELO, F., TULADHAR, R. (Eds.), Use of Recycled 
Plastics in Eco-Efficient Concrete. Woodhead Publishing

98. Singh, N.K. Rai, B. A review of fiber synergy in hybrid fiber reinforced concrete, J. Appl. Eng. Sci. 8 (2018) 41-50, doi:http://dx.doi.org/10.2478/jaes- 2018-0017.

99. Sivakumar, A. Santhanam M. Mechanical properties of high strength concrete reinforced with metallic and non-metallic fibres Cem. Concr. Compos., 29 (2007a), pp. 603-608,

10.1016/j.cemconcomp.2007.03.006

100. Sivakumar, A. Santhanam, M. A quantitative study on the plastic shrinkage cracking in high strength hybrid fibre reinforced concrete, Cem. Concr. Compos. 29 (2007b) 575-581, doi:http://dx.doi.org/10.1016/j.cemconcomp.2007.03.005

101. T.W. Ahmed, A.A.M. Ali, R.S. Zidan, Properties of high strength polypropylene fiber concrete containing recycled aggregate, Constr. Build. Mater. 241 (2020) 118010, doi:http://dx.doi.org/10.1016/j.conbuildmat.2020.118010.

102. Wan Ibrahim, M.H. Mangi, S.A. Burhanudin, M.K. Ridzuan, M.B. Jamaluddin, NShahidan, S. Wong, Y. Faisal, S. Fadzil, M.A. Ramadhansyah P.J, Ayop, S.S. Othman, N.H Compressive and flexural strength of concrete containing palm oil biomass clinker and polypropylene fibres, IOP Conf. Ser. Mater. Sci. Eng. 271 (2017) 012011, doi:http://dx.doi.org/10.1088/1757-899X/271/1/012011.

103. Widodo, S. Fresh and hardened properties of polypropylene fiber added self-consolidating concrete, Int. J. Civ. Struct. Environ. Infrastruct. Eng. Res. Dev. 3 (2012) 3008, doi:http://dx.doi.org/10.6088/ijcser.201203013008.

104. Xiang, Y. Song, Q. Gu. W. 2020: Decontamination of surgical face masks and N95 respirators by dry heat pasteurization for one hour at $70^{\circ} \mathrm{C}$. Am. J. Infect. Control, 48 (8) (2020), pp. 880-882

105. Xu, H., Shao, Z., Wang, Z., Cai, L., Li, Z., Jin, H., Chen, T., 2020. Experimental study on mechanical properties of fiber reinforced concrete: effect of cellulose fiber,

106. Y. Lin, D. Gao, Y. Zhang, et al., Study on water and chloride transport in cracked mortar using X-ray $\mathrm{CT}$, gravimetric method and natural immersion method,

107. Yang, J. Wang, R. Zhang, Y. Influence of dually mixing with latex powder and polypropylene fiber on toughness and shrinkage performance of overlay repair mortar, Constr. Build. Mater. 261 (2020) 120521, doi:http://dx.doi.org/10.1016/j.conbuildmat.2020.120521.

108. Yap, S.P. Bu, C.H. Alengaram, U.J Mo, K.H. Jumaat, M.Z. Flexural toughness characteristics of steelpolypropylene hybrid fibre-reinforced oil palm shell concrete, Mater. Des. 57 (2014) 652-659, doi:http://dx.doi.org/10.1016/j.matdes.2014.01.004.

109. Yap, S.P., Alengaram, U.J., Jumaat, M.Z., 2013. Enhancement of mechanical properties in polypropylenee and nylonefibre reinforced oil palm shell concrete. Mater.

110. Yin, S., Tuladhar, R., Shi, F., Combe, M., Collister, T., Sivakugan, N., 2015. Use of macro plastic fibres in concrete: a review. Construct. Build. Mater. 93, 180e188.

111. Z.J. Grdic, G.A.T. Curcic, N.S. Ristic, I.M. Despotovic, Abrasion resistance of concrete micro-reinforced with polypropylene fibers, Constr. Build. Mater. 27 (2012) 305-312, doi:http://dx.doi.org/10.1016/j.conbuildmat.2011.07.044. 
112. Zych T., Krasodomski, W. Polyolefin fibres used in cementitious composites-manufacturing, properties and application, Tech. Trans. Civ. Eng. 3 (2016) 155-178, doi:http://dx.doi.org/10.4467/2353737XCT.16.223.5972.

\section{Figures}

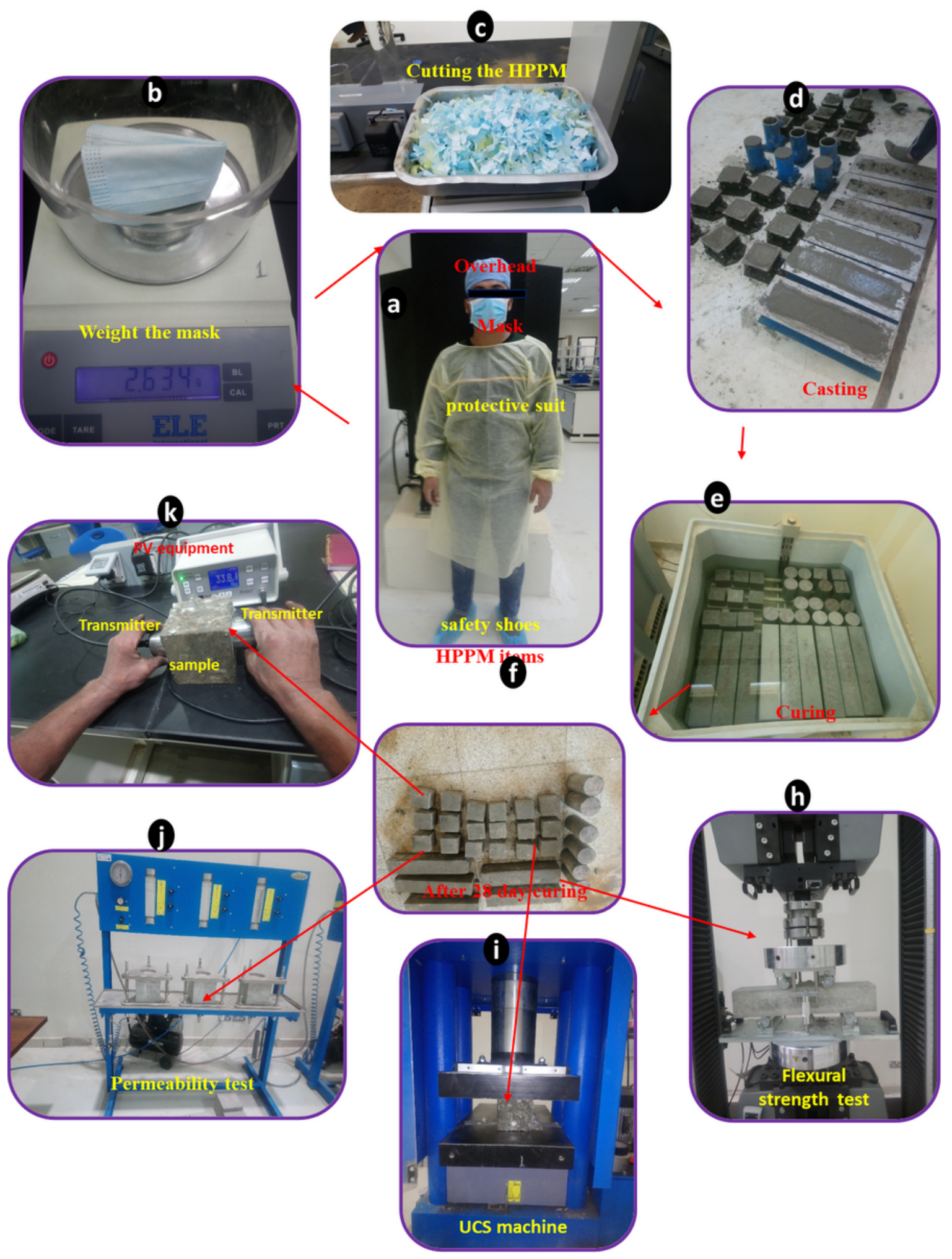

Figure 1 
Experimentation protocols, casting and curing of the concrete with HPPM.

a

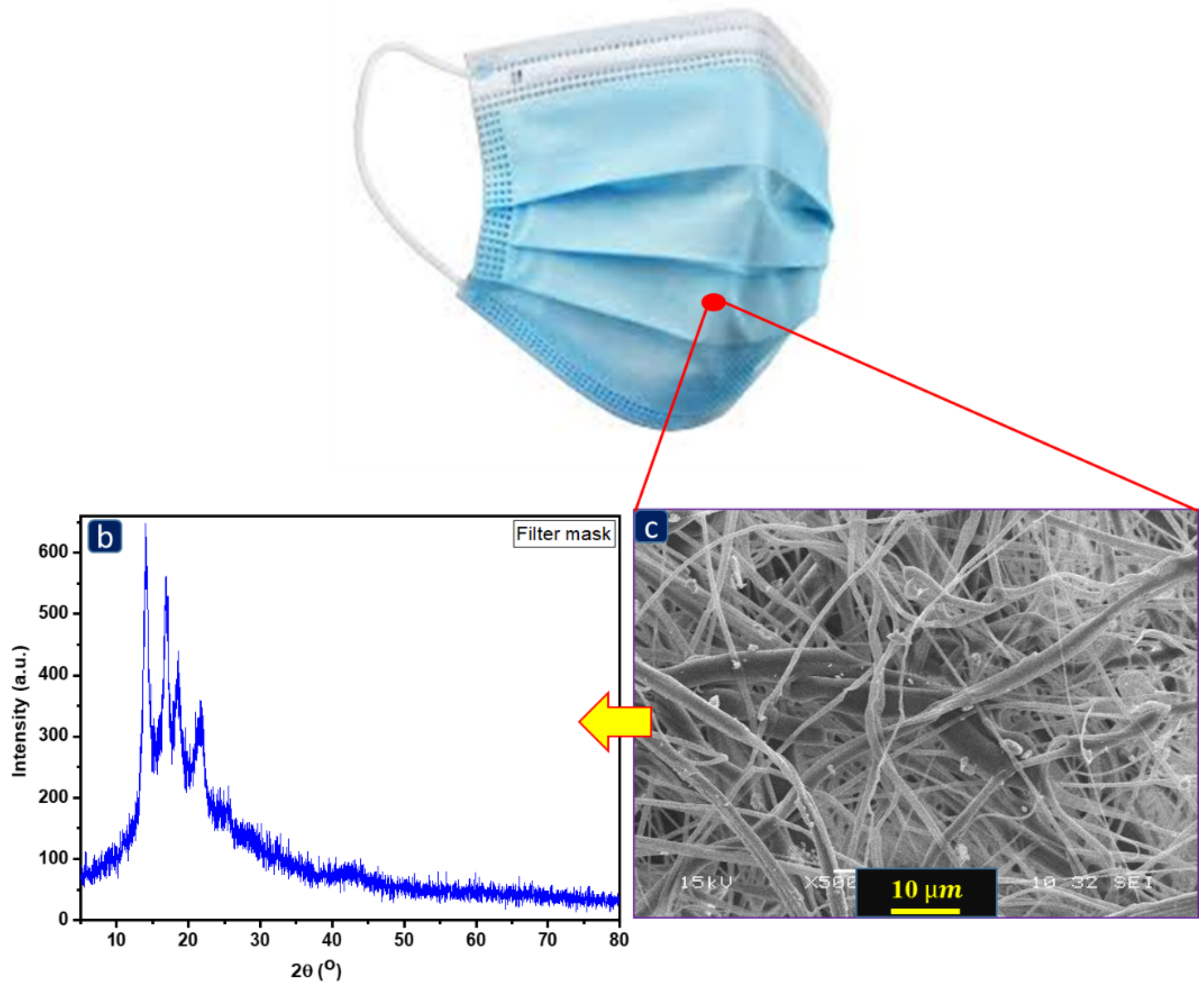

Figure 2

a) Single used Face mask, b) XRD image of FM fibers, c) appearance of face mask layers under scanning electron microscope at 1000x. 


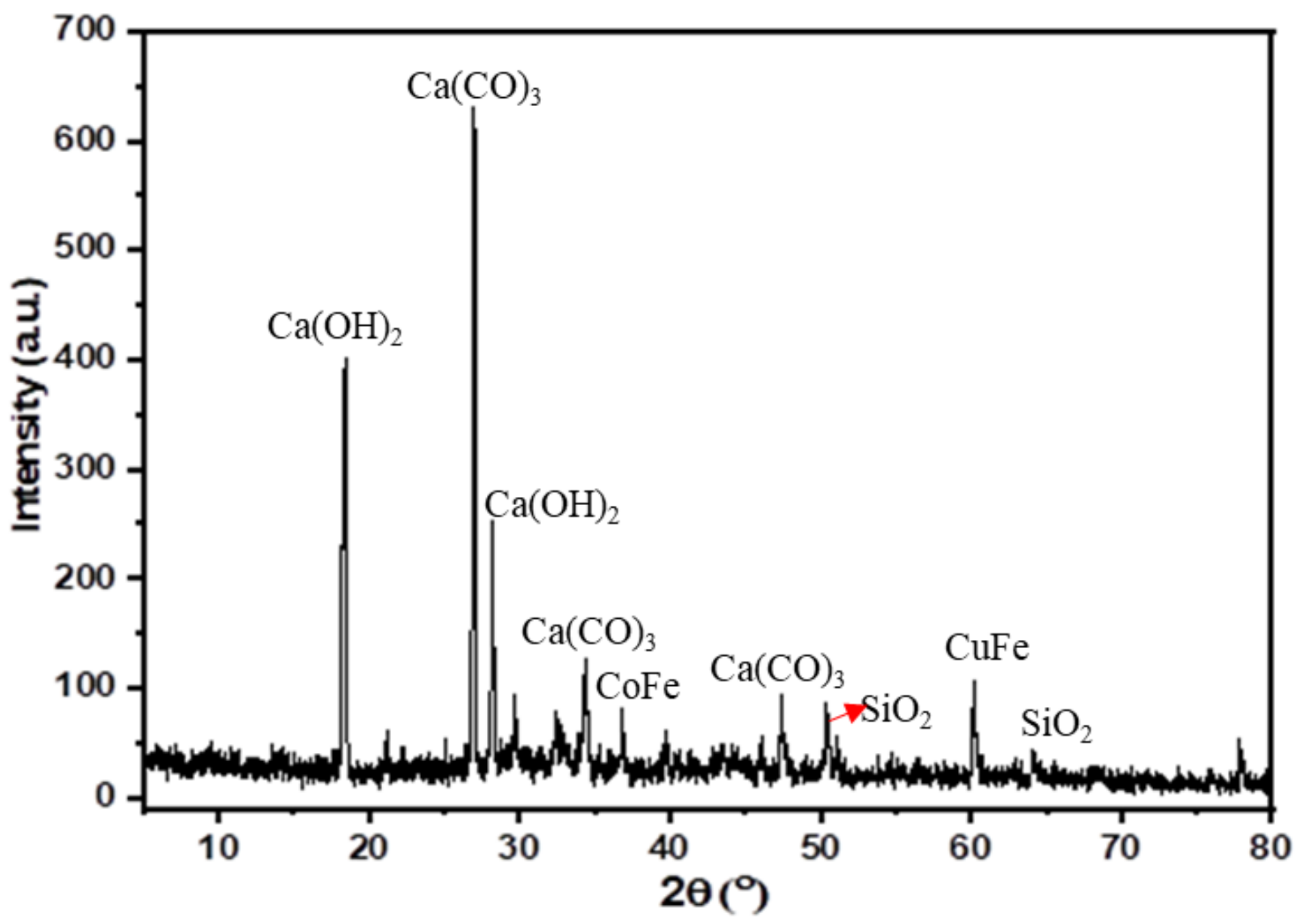

Figure 3

XRD analysis of concrete with 2\% HPPM after 28 days. 


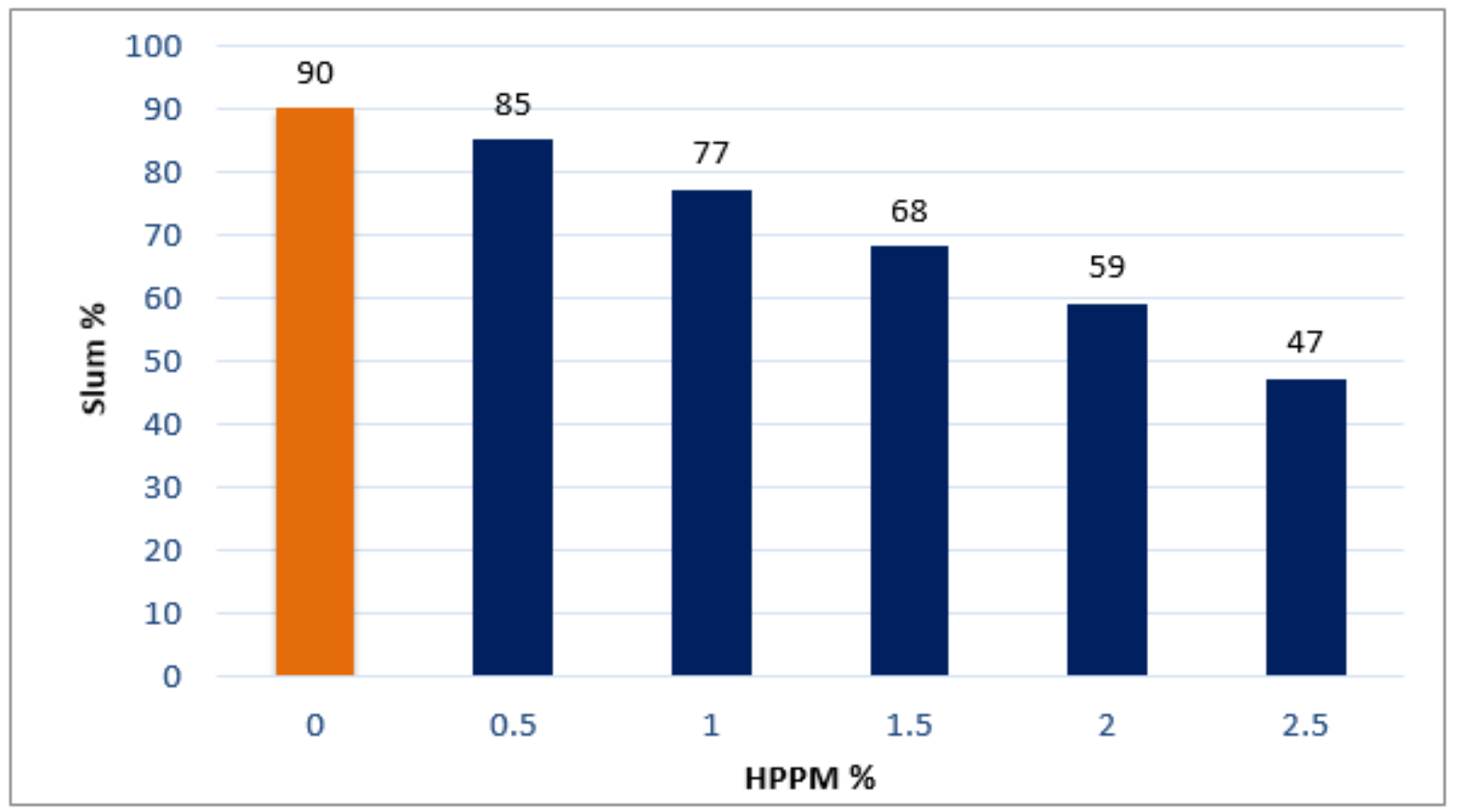

Figure 4

Slump of different percentage of HPPM.

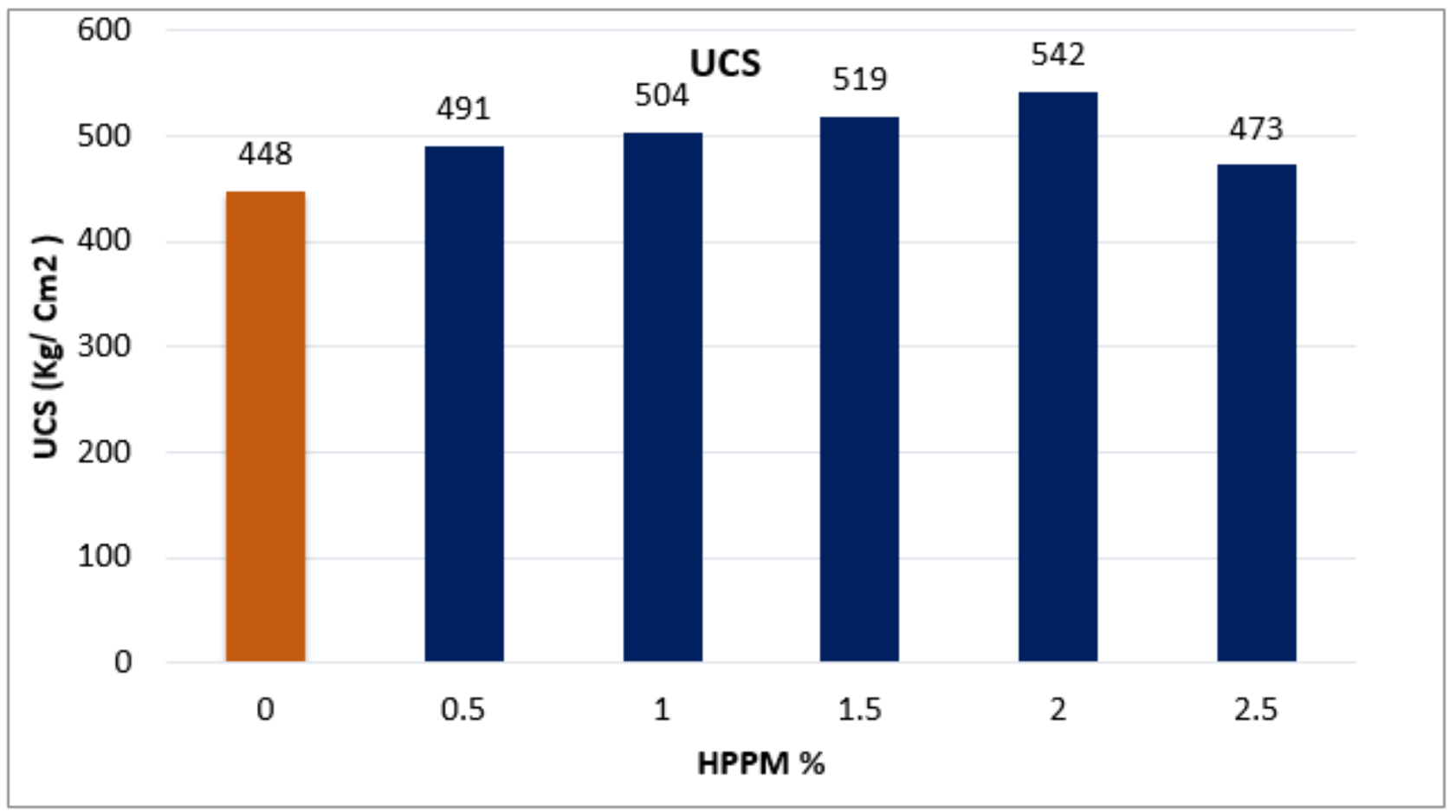

Figure 5

Compressive strength results after 28-day enhanced by the adding of HPPM. 

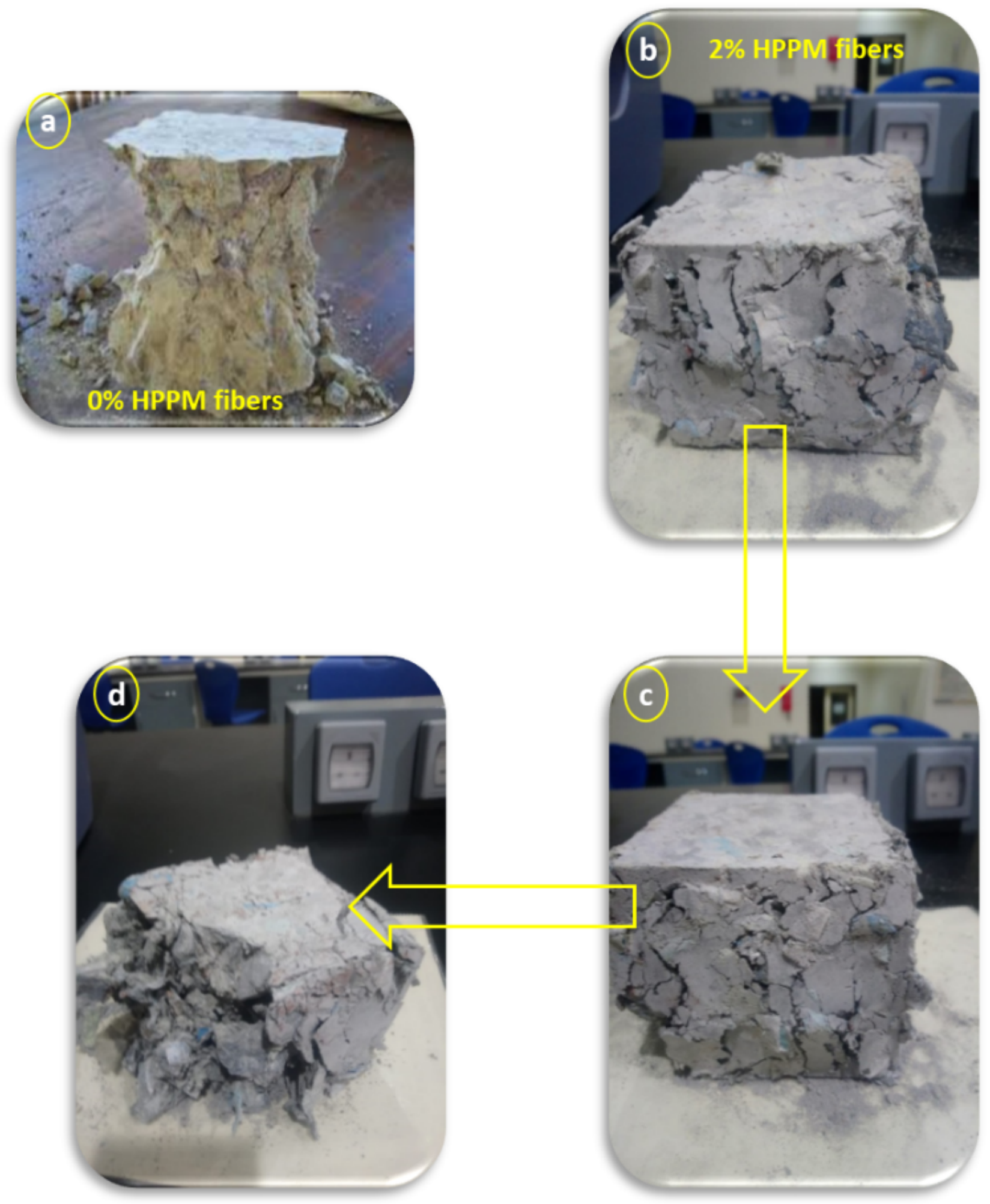

Figure 6

Failure mode of concrete specimens under compression load 

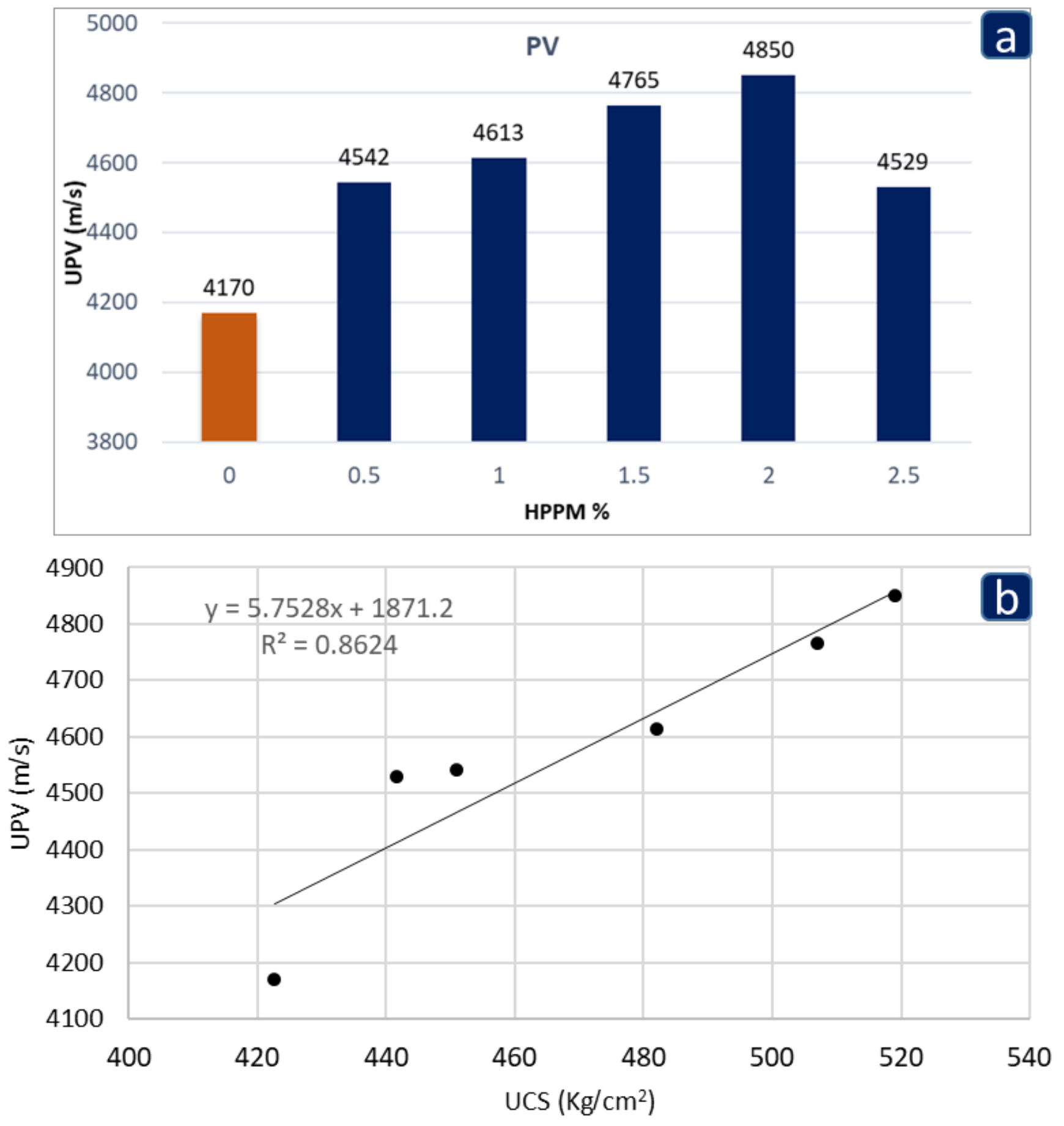

Figure 7

a) P-wave velocity results after 28-day b) relationship between UCS and PV for concrete contain HPPM. 


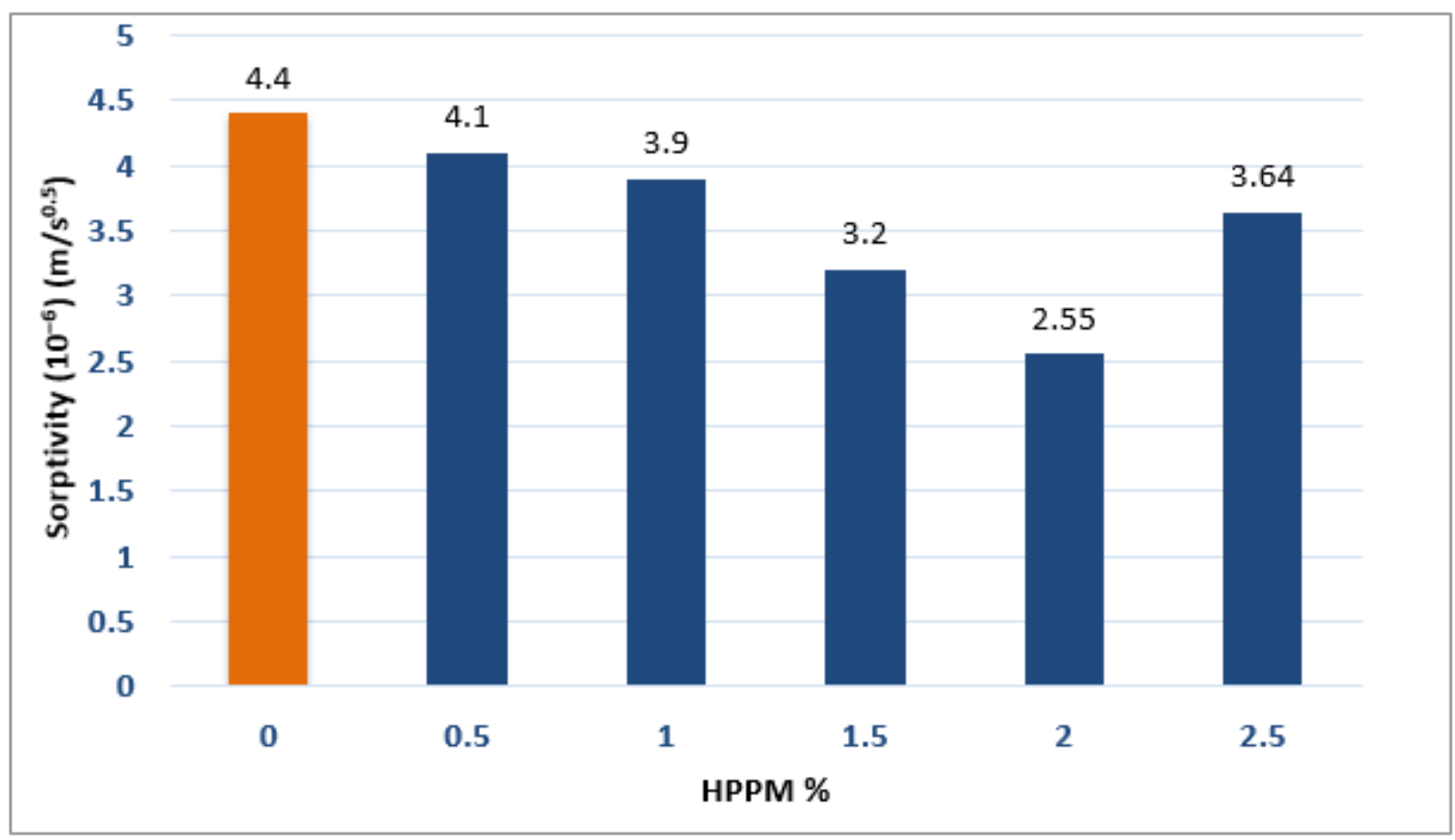

Figure 8

Sorptivity enhancement after 28-day enhanced by the adding of HPPM. 

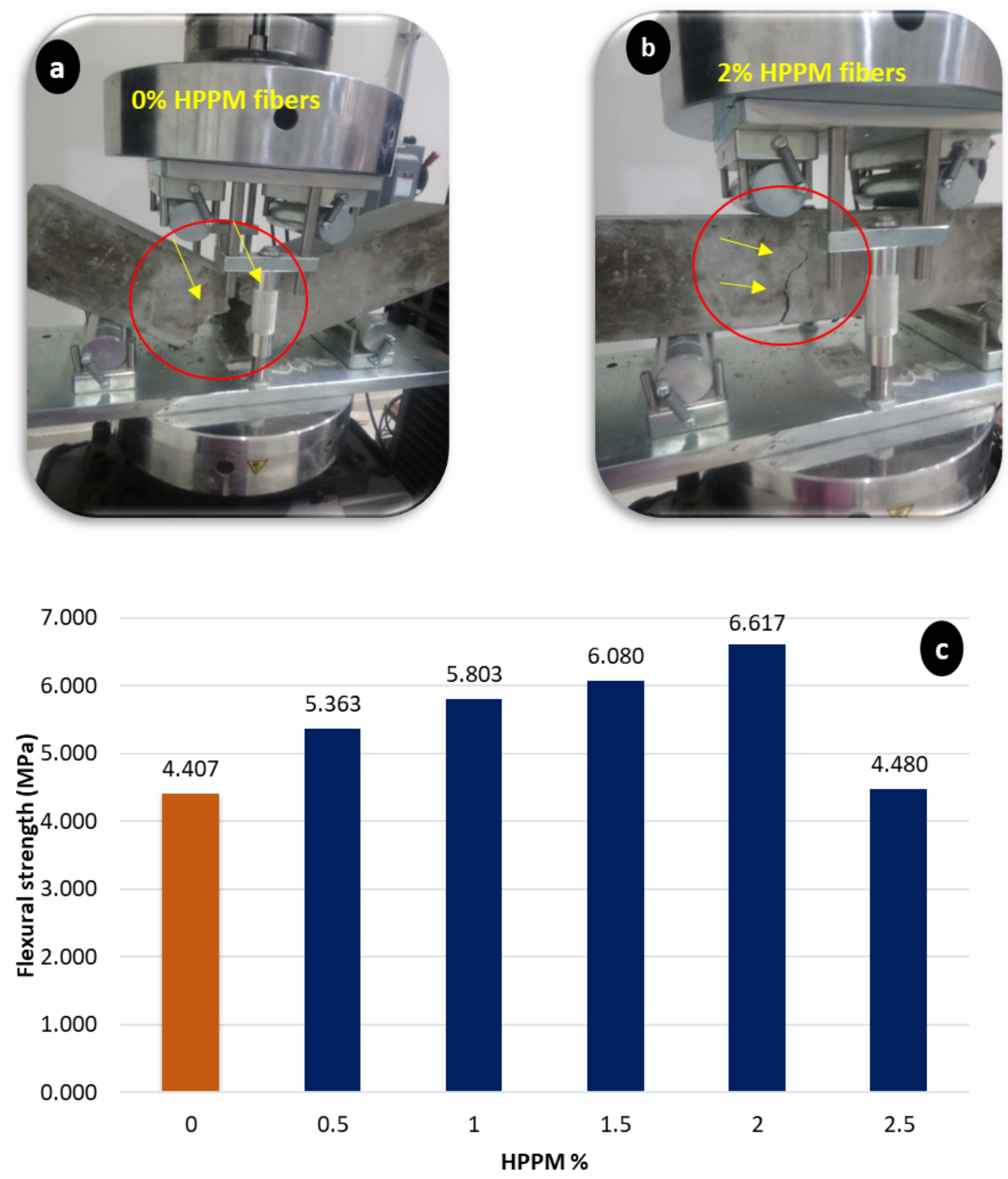

Figure 9

Flexural strength enhancement after 28-day enhanced by the adding of HPPM. 


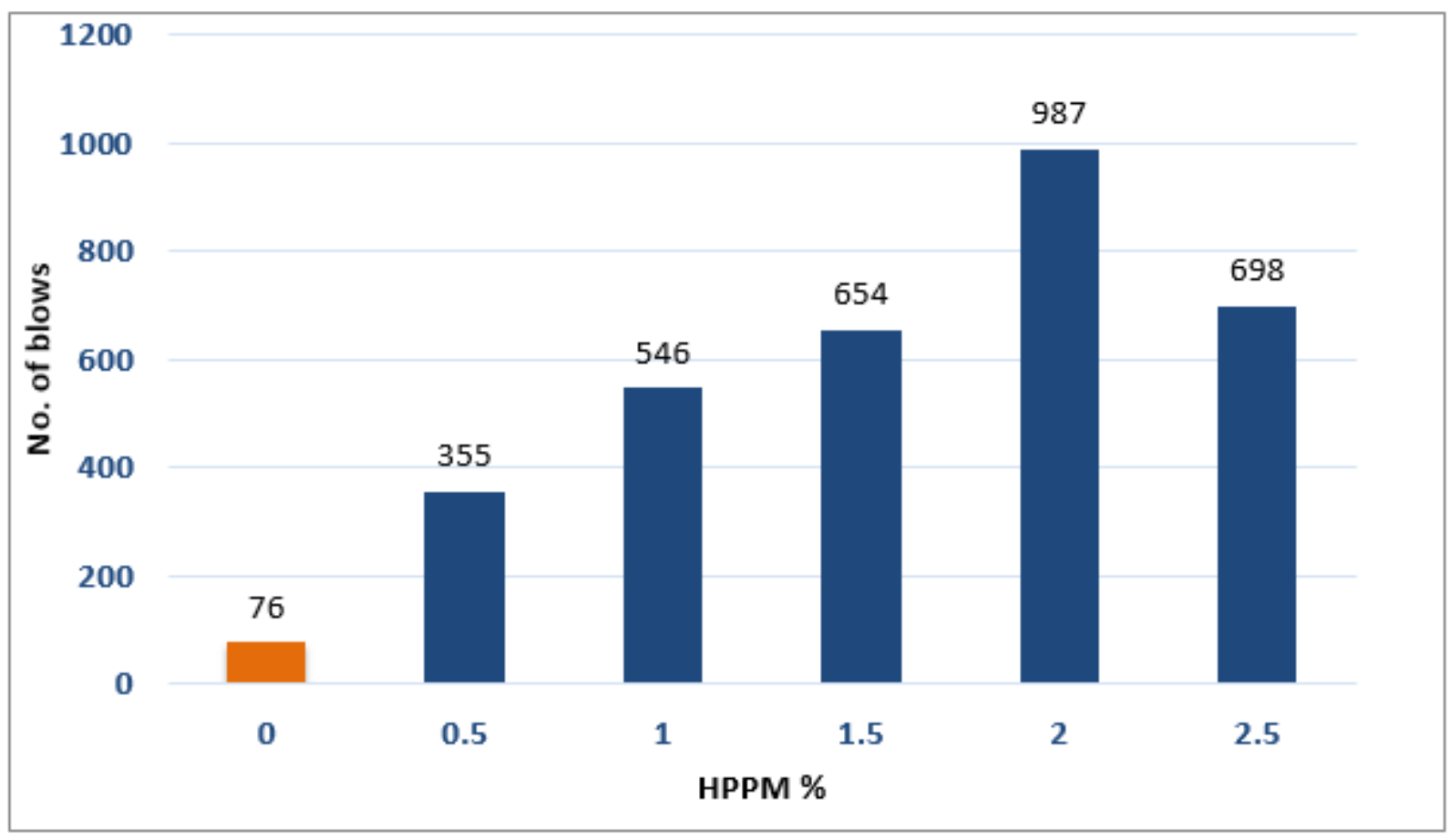

Figure 10

Influence of HPPM incorporation on Impact resistance.

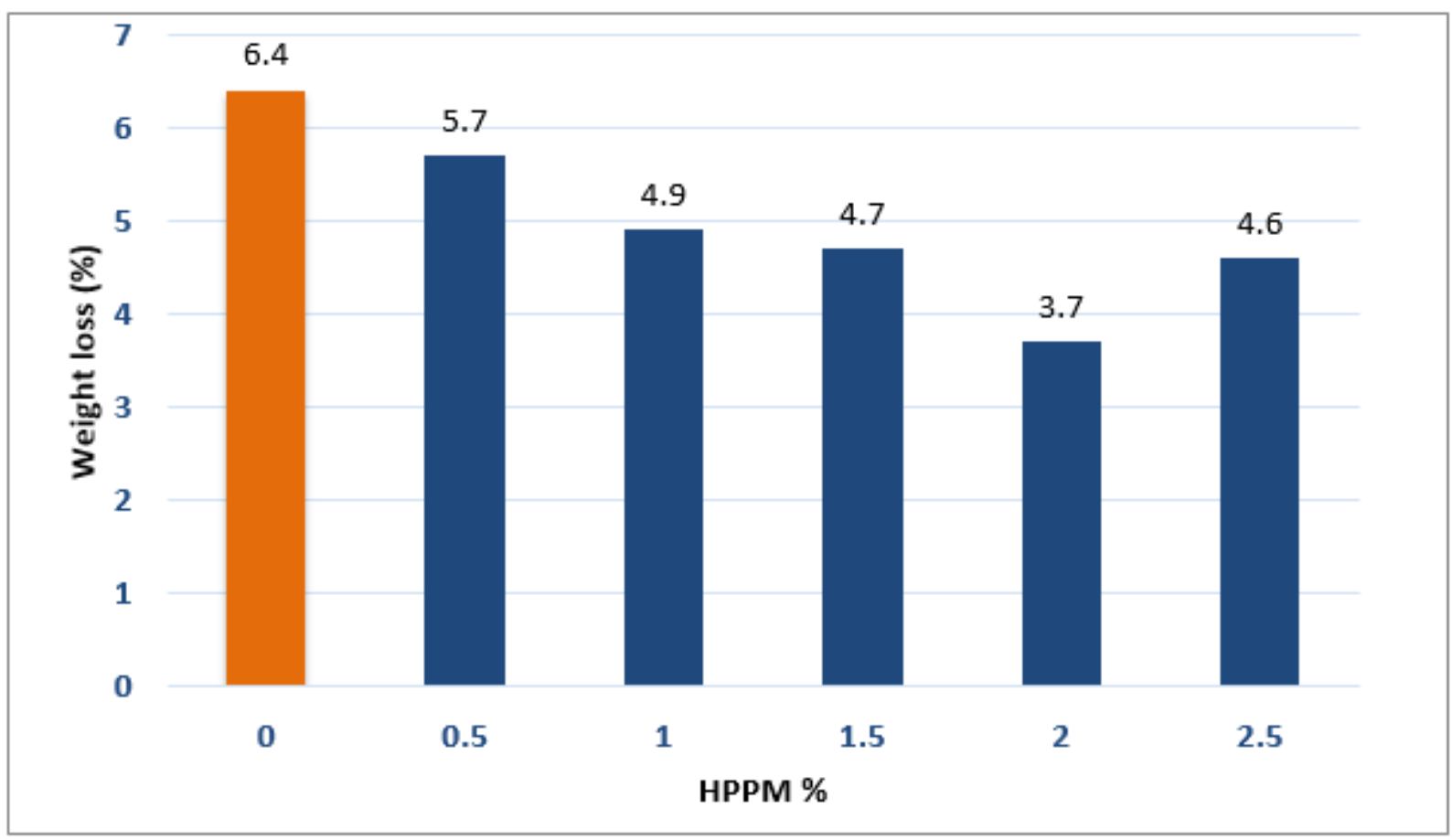

Figure 11

Abrasion resistance enhancement after 28-day enhanced by the adding of HPPM. 

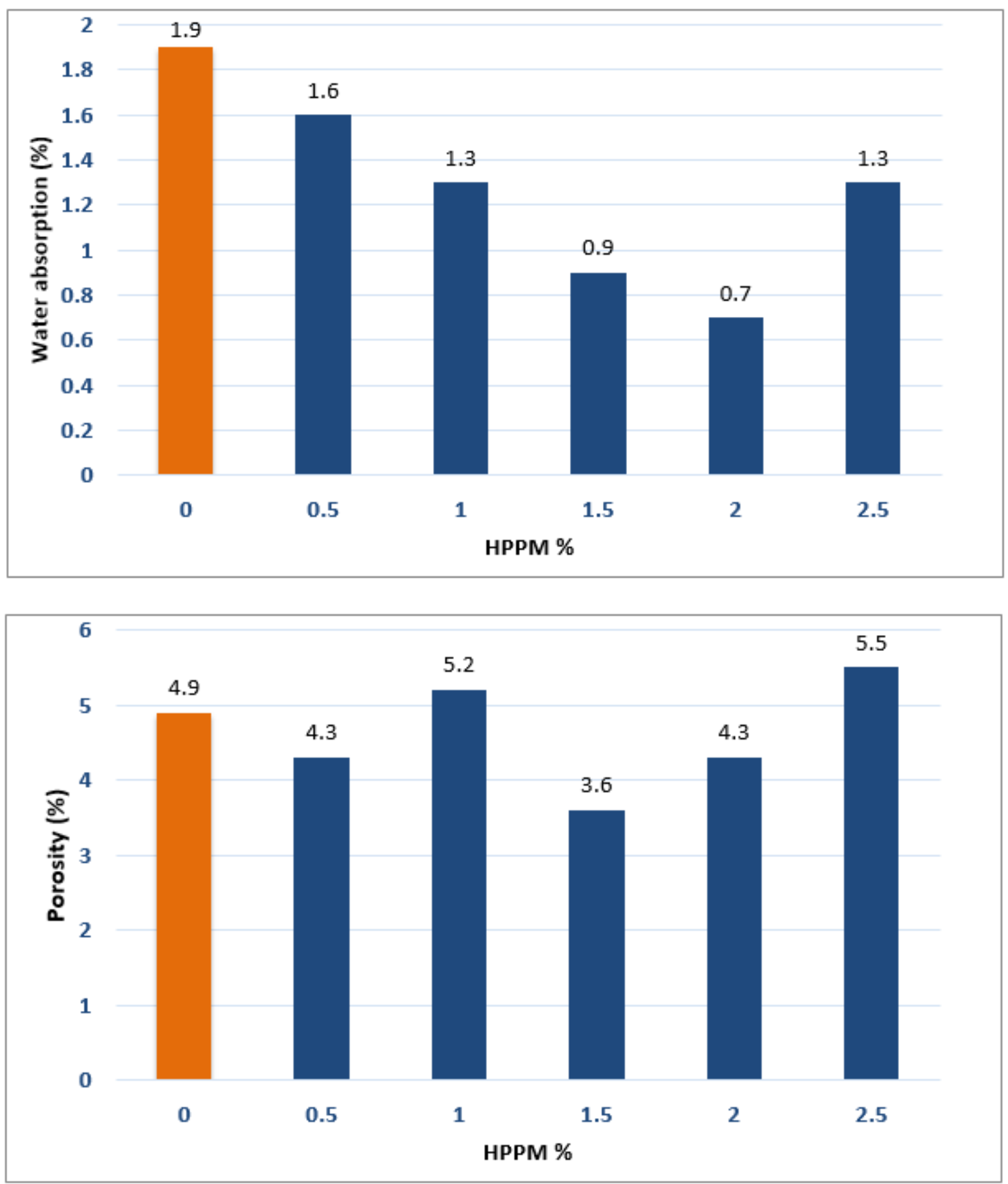

Figure 12

Influence of HPPM on a) water absorption "SW"; b) porosity, " $n$ " reported in selected studies. 


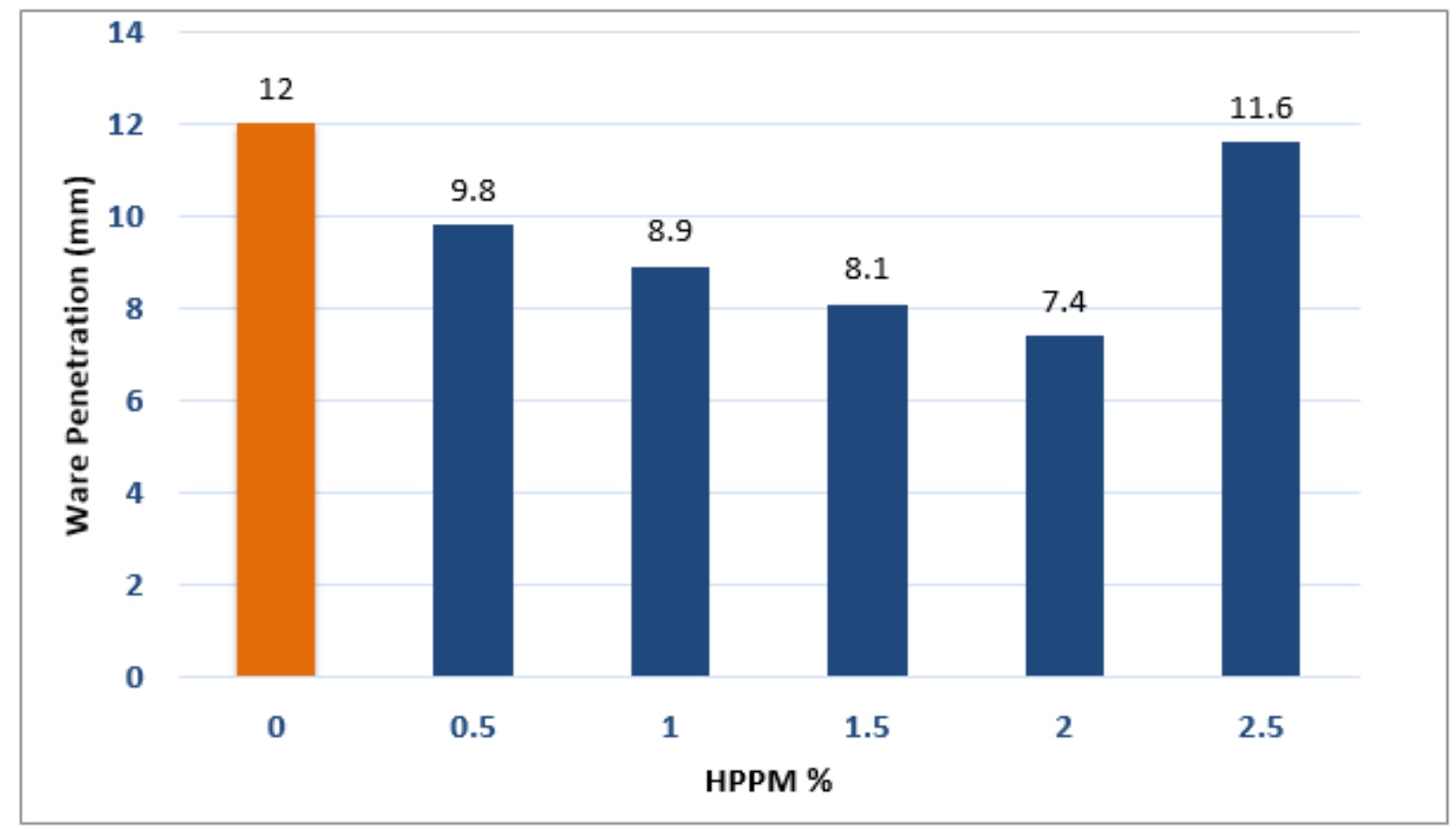

Figure 13

Depth of Water penetration vs HPPM fiber content after 28 days. 


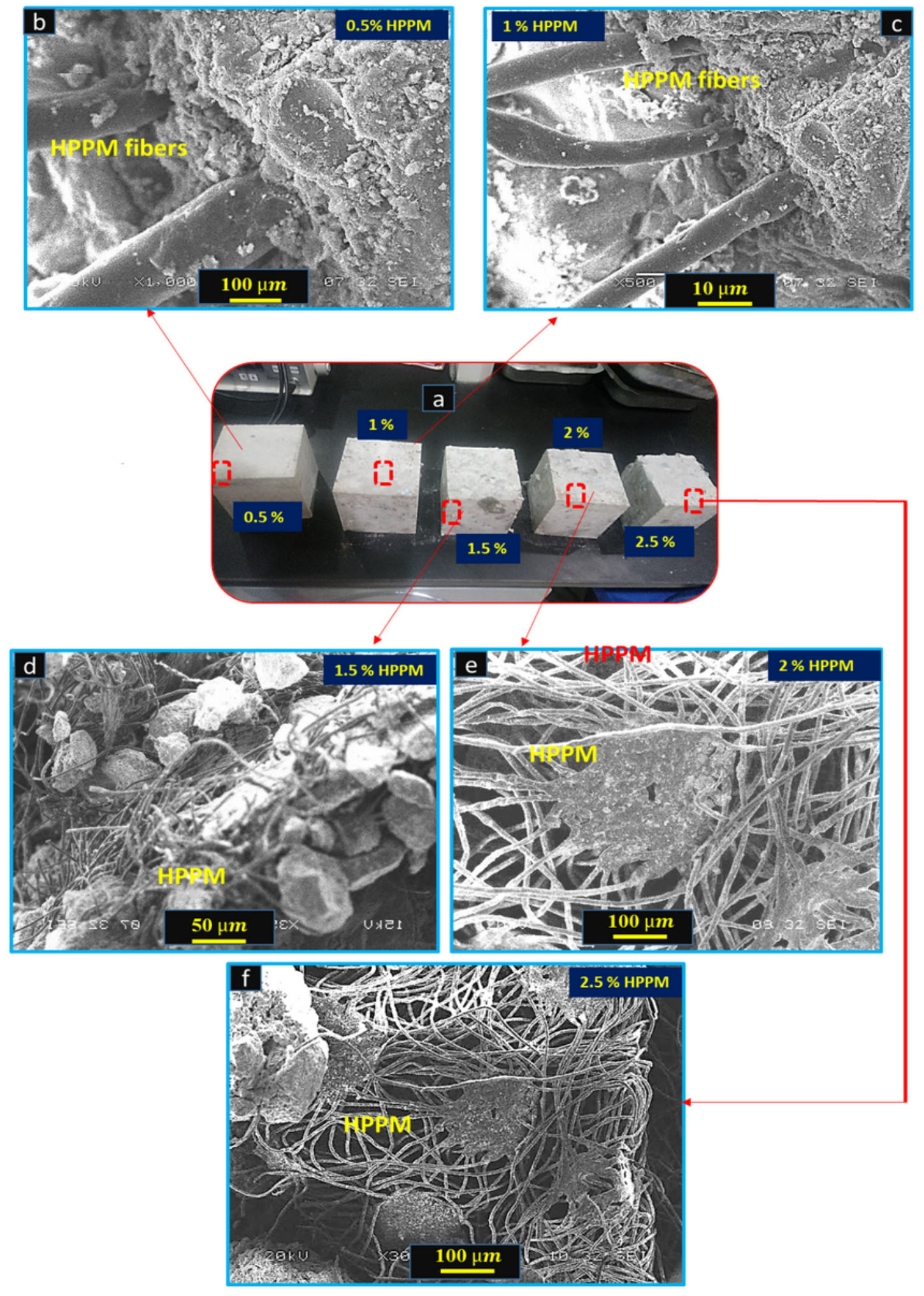

Figure 14

SEM images of concrete with HPPM fibers. (a) cubes with different percentage of HPPM, (b, c, d, e, f) $0.5 \%, 1 \%, 1.5 \% .2 \%$ and $2.5 \%$ of HPPM fibers. 


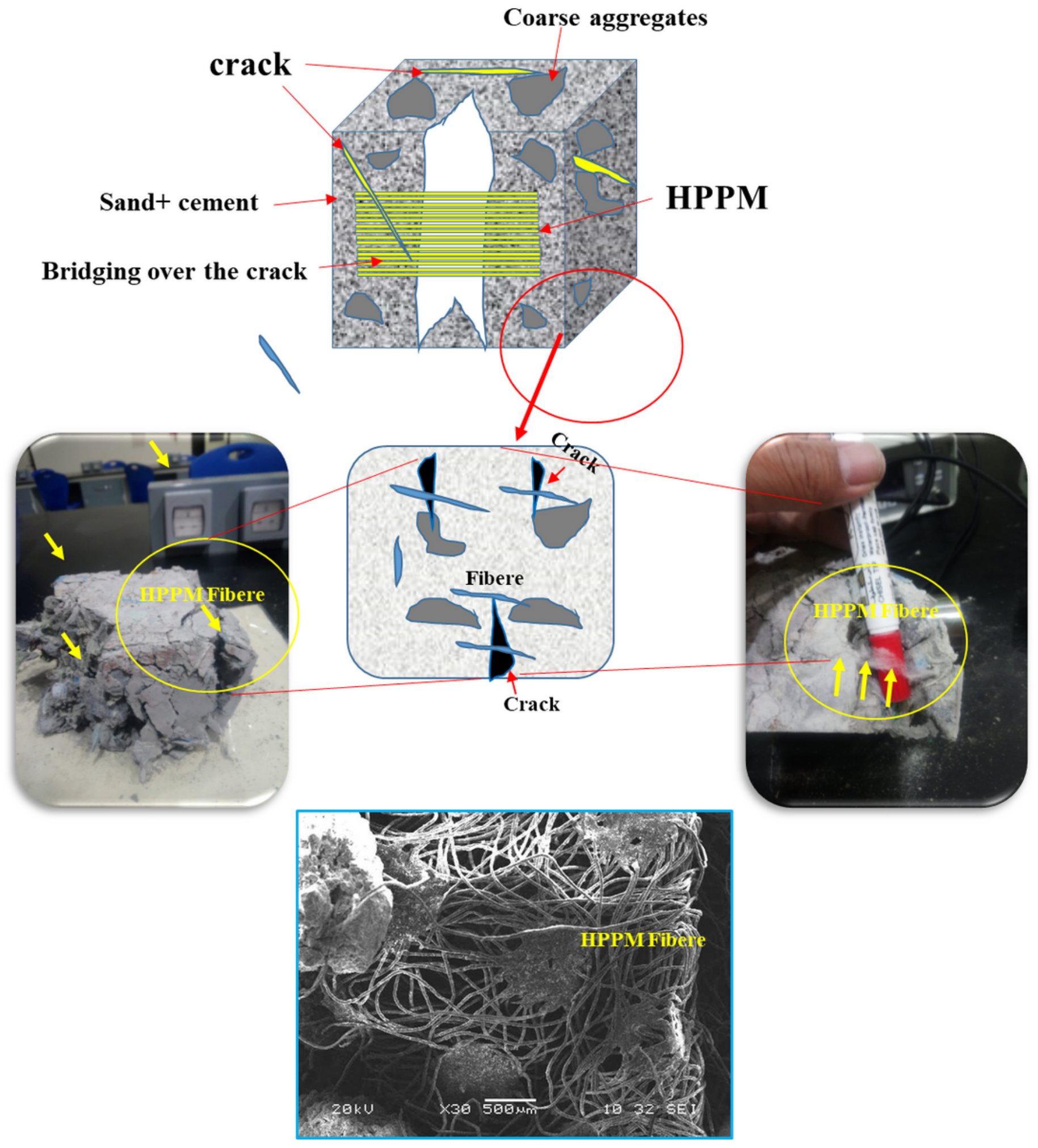

Figure 15

Schematic representation of mechansim of brdiging formed by HPPM fibres. 